NASA/TM-2015-218968

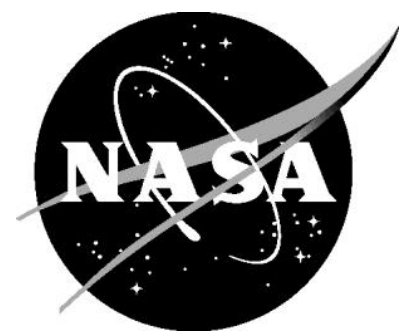

\title{
Verification and Validation of the k-kL Turbulence Model in FUN3D and CFL3D Codes
}

Khaled S. Abdol-Hamid, Jan-Renee Carlson, and Christopher L. Rumsey

Langley Research Center, Hampton, Virginia 


\section{NASA STI Program . . . in Profile}

Since its founding, NASA has been dedicated to the advancement of aeronautics and space science. The NASA scientific and technical information (STI) program plays a key part in helping NASA maintain this important role.

The NASA STI program operates under the auspices of the Agency Chief Information Officer. It collects, organizes, provides for archiving, and disseminates NASA's STI. The NASA STI program provides access to the NTRS Registered and its public interface, the NASA Technical Reports Server, thus providing one of the largest collections of aeronautical and space science STI in the world. Results are published in both non-NASA channels and by NASA in the NASA STI Report Series, which includes the following report types:

- TECHNICAL PUBLICATION. Reports of completed research or a major significant phase of research that present the results of NASA Programs and include extensive data or theoretical analysis. Includes compilations of significant scientific and technical data and information deemed to be of continuing reference value. NASA counter-part of peer-reviewed formal professional papers but has less stringent limitations on manuscript length and extent of graphic presentations.

\section{- TECHNICAL MEMORANDUM.}

Scientific and technical findings that are preliminary or of specialized interest, e.g., quick release reports, working papers, and bibliographies that contain minimal annotation. Does not contain extensive analysis.

- CONTRACTOR REPORT. Scientific and technical findings by NASA-sponsored contractors and grantees.
- CONFERENCE PUBLICATION.

Collected papers from scientific and technical conferences, symposia, seminars, or other meetings sponsored or co-sponsored by NASA.

- SPECIAL PUBLICATION. Scientific, technical, or historical information from NASA programs, projects, and missions, often concerned with subjects having substantial public interest.

- TECHNICAL TRANSLATION. English-language translations of foreign scientific and technical material pertinent to NASA's mission.

Specialized services also include organizing and publishing research results, distributing specialized research announcements and feeds, providing information desk and personal search support, and enabling data exchange services.

For more information about the NASA STI program, see the following:

- Access the NASA STI program home page at http://www.sti.nasa.gov

- E-mail your question to help@ @sti.nasa.gov

- Phone the NASA STI Information Desk at 757-864-9658

- Write to:

NASA STI Information Desk

Mail Stop 148

NASA Langley Research Center

Hampton, VA 23681-2199 
NASA/TM-2015-218968

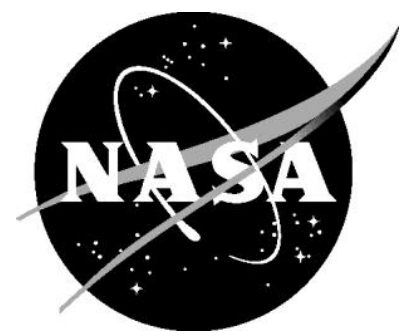

\section{Verification and Validation of the k-kL Turbulence Model in FUN3D and CFL3D Codes}

Khaled S. Abdol-Hamid, Jan-Renee Carlson, and Christopher L. Rumsey

Langley Research Center, Hampton, Virginia 
The use of trademarks or names of manufacturers in this report is for accurate reporting and does not constitute an official endorsement, either expressed or implied, of such products or manufacturers by the National Aeronautics and Space Administration.

Available from:

NASA STI Program / Mail Stop 148

NASA Langley Research Center

Hampton, VA 23681-2199

Fax: 757-864-6500 


\section{Abstract}

The implementation of the k-kL turbulence model using multiple computational fluid dynamics (CFD) codes is reported herein. The k-kL model is a two-equation turbulence model based on Abdol-Hamid's closure and Menter's modification to Rotta's two-equation model. Rotta shows that a reliable transport equation can be formed from the turbulent length scale $\mathrm{L}$, and the turbulent kinetic energy k. Rotta's equation is well suited for term-by-term modeling and displays useful features compared to other two-equation models. An important difference is that this formulation leads to the inclusion of higher-order velocity derivatives in the source terms of the scale equations. This can enhance the ability of the Reynoldsaveraged Navier-Stokes (RANS) solvers to simulate unsteady flows. The present report documents the formulation of the model as implemented in the CFD codes Fun3D and CFL3D. Methodology, verification and validation examples are shown. Attached and separated flow cases are documented and compared with experimental data. The results show generally very good comparisons with canonical and experimental data, as well as matching results code-to-code. The results from this formulation are similar or better than results using the SST turbulence model.

\section{Nomenclature}

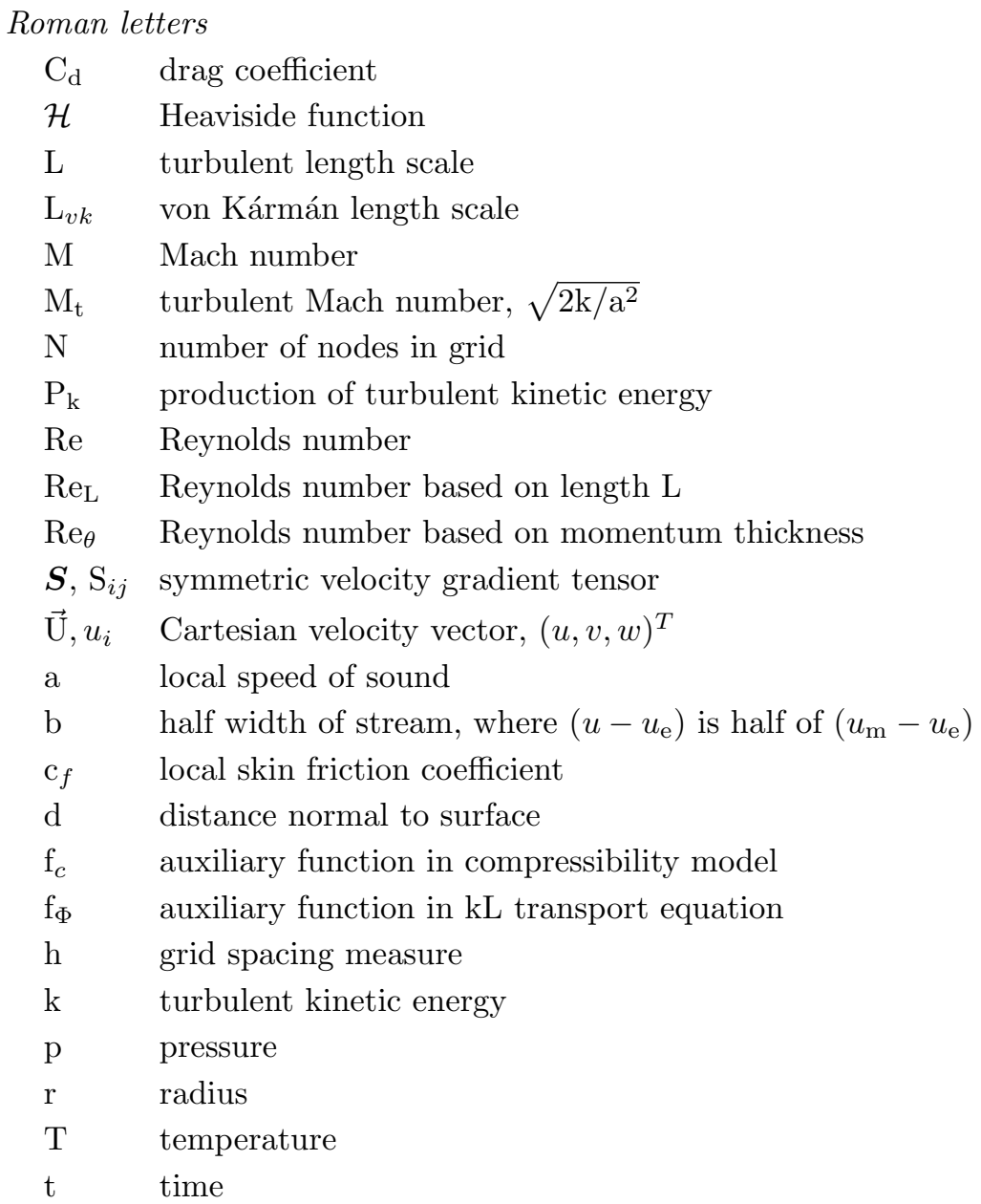


$u_{\mathrm{e}} \quad$ velocity at edge of outer planar shear stream

$u_{\mathrm{m}} \quad$ peak velocity of planar shear stream

$\mathrm{u}^{+} \quad$ velocity in wall units

$x_{i} \quad$ Cartesian coordinates, $(x, y, z)$

$\mathrm{y}^{+} \quad$ distance normal from surface in wall units

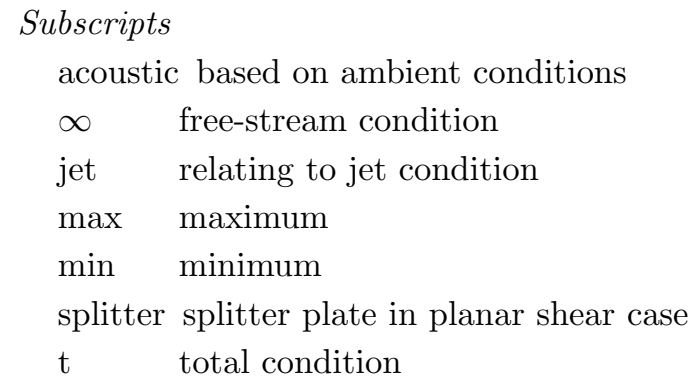

Conventions

2D two dimensional

ARN acoustic research nozzle

CFD computational Fluid Dynamics

C-D convergent-divergent

EASM explicit algebraic Reynolds stress

LES large eddy simulation

NPR nozzle pressure ratio, $p_{t, j e t} / p_{\infty}$

NTR nozzle temperature ratio, $T_{t, j e t} / T_{\infty}$

RANS Reynolds averaged Navier-Stokes

SAS scale-adaptive simulation

SST shear stress transport

URANS unsteady Reynolds averaged Navier-Stokes

$\begin{array}{cl}\text { Symbols } & \\ \delta_{i j} & \text { Kronecker delta } \\ \varepsilon & \text { scalar dissipation } \\ \theta & \text { momentum thickness } \\ \kappa & \text { von Kármán constant } \\ \mu & \text { bulk viscosity } \\ \mu_{\mathrm{t}} & \text { turbulent eddy viscosity } \\ \omega & \text { specific dissipation rate } \\ \Phi & \text { kL } \\ \rho & \text { density } \\ \tau_{i j} & \text { Reynolds stress tensor }\end{array}$

\footnotetext{
Superscripts

' first derivative

" second derivative
} 


\section{Introduction}

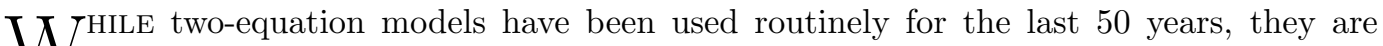
based on the Reynolds stress equations and, typically, a modeled length scale. The mechanism of the second equation for determining turbulent length scale is not fully understood and a number of formulations use a special boundary condition for simulating its wall boundary condition. Even the more complex model closures like Reynolds stress models (RSM), or explicit algebraic Reynolds stress models (EASM) still use a length scale equation based on an underlying two-equation model. Almost all two-equation models use the turbulent kinetic energy, $\mathrm{k}$, and its transport equation as one of the primary variables.

Historically, the modeling of the second equation using dimensional arguments has been purely heuristic [1]. Many of the models for the production are only using strain-rate or vorticity derived from the mean flow terms, resulting in only one scale from the equilibrium of source terms for both equations. The second equation is considered, in most cases, the weakest link in turbulence models, including much more complex approaches such as differential Reynolds stress and hybrid RANS/LES formulations. It is difficult to justify using any of the complex turbulence models without fixing or using an alternate form for the second transport equation. One of the few exceptions is the modeling concept proposed by Rotta [2], which can be formed as an exact transport equation for the turbulent length scale, L. Rotta's approach is well suited for term-by-term modeling and displays very favorable characteristics, as compared to other approaches. A key difference is the inclusion of higherorder velocity derivatives in the source terms of the scale equation. This potentially allows for resolution of the turbulent spectrum in unsteady flows.

Menter et al. [3-5] presented a complete form of the $\mathrm{k}-\sqrt{\mathrm{k}} \mathrm{L}$ two-equation turbulence model based on the Rotta [2] approach. In Menter, it was proposed to replace the problematic third derivative of the velocity, that occurred in Rotta's original model, with second derivatives of the velocity. Menter utilized this two-equation turbulence model to formulate the Scale-Adaptive Simulation (SAS) term that can be added to other two-equation models, such as Menter's SST [6]. The SAS concept is based on the introduction of the von Kármán length scale into the turbulence scale equation. The information provided by the von Kármán length scale allows SAS models to dynamically adjust to resolved structures in unsteady RANS (URANS) simulations. This can create LES-like behavior in unsteady regions of flowfields. At the same time, the model provides standard RANS capabilities in stable flow regions.

Abdol-Hamid [7] documented an initial form of the k-kL two-equation turbulence model. The reference showed the process to calibrate the constants within the range suggested by Rotta [2] and satisfying the near-wall logarithmic requirements. This model does not use a blending function to merge two turbulence scale equations as is done with the SST model, or have the near-wall damping functions typical of $\mathrm{k}-\varepsilon$ turbulence models. It naturally contains the SAS characteristics through the von Kármán length scale. The basic model was implemented in the CFD code PAB3D [8]. The formulations, usage methodology, and validation examples were compiled and presented to demonstrate the capabilities of the model. The model provides proper RANS performance in stable flow regions and allows the break-up of large turbulent structures for unstable flow regions, for example a cylinder in cross-flow or flow in a cavity.

In the present report, we document the $\mathrm{k}-\mathrm{kL}$ model and the process to implement it in CFD solvers. The model (with a few very minor differences from the model originally implemented in PAB3D) is in both the unstructured code FUN3D and the multiblock structured code CFL3D. This new model version is named k-kL-MEAH2015. This report shows the comparisons between the results generated from both codes to validate and verify the implementations. Results for all near-wall flows have been calculated using the grids that resolve the viscous sublayer with $\mathrm{y}^{+}<1$. Simulations have been carried out using 5 grid 
levels for the verification cases, avoiding grid refinement uncertainties. The validation results are compared with available experimental and/or theoretical data, depending upon the case. Most of the cases are taken from the turbulence modeling resource website $[9,10]$.

Subsonic and supersonic jet flows are quite difficult to predict with most RANS turbulence models. For subsonic jets, most turbulence models incorrectly predict the mixing rate so that the jet core length differs significantly from what is physically observed. The k-kL model also predicts a core length that is too short. A proposed jet correction, including compressibility effects, is described and is designated k-kL-MEAH2015+J.

\section{Turbulence Model Description}

The baseline k-kL turbulence is described in 2.1. Models to correct for free shear flows and compressibility effects are described in section 2.2 .

\subsection{Baseline k-kL Model}

The k-kL-MEAH2015 two-equation turbulence model, Eqs. 1 through 12 , is based on the approach of Menter [3-5] to develop a $\mathrm{k}-\sqrt{\mathrm{k}} \mathrm{L}$ model. A complete list of coefficients used by the present model is defined. The model is based on Rotta's k-kL $(\Phi=\mathrm{kL})$ with the modifications proposed by Menter where the third derivative of velocity was replaced with the second derivative of velocity. The closure constants were derived and documented by Abdol-Hamid [7]. The current version, k-kL-MEAH2015, is slightly different from the earlier version, k-kL-MEAH2013, that was reported by Abdol-Hamid [7].

$$
\begin{aligned}
& \frac{\partial}{\partial t} \rho \mathrm{k}+\nabla \cdot(\rho \overrightarrow{\mathrm{U}} \mathrm{k})=\mathrm{P}_{\mathrm{k}}-\mathrm{C}_{\mathrm{k}} \rho \frac{\mathrm{k}^{5 / 2}}{(\mathrm{~kL})}-2 \mu \frac{\mathrm{k}}{\mathrm{d}^{2}}+\nabla \cdot\left[\left(\mu+\sigma_{\mathrm{k}} \mu_{\mathrm{t}}\right) \nabla \mathrm{k}\right] \\
& \frac{\partial}{\partial t} \rho(\mathrm{kL})+\nabla \cdot(\rho \overrightarrow{\mathrm{U}}(\mathrm{kL}))=\mathrm{C}_{\phi_{1}} \frac{(\mathrm{kL})}{\mathrm{k}} \mathrm{P}_{\mathrm{k}}-\mathrm{C}_{\phi_{2}} \rho \mathrm{k}^{3 / 2}- 6 \mu \frac{(\mathrm{kL})}{\mathrm{d}^{2}} f_{\Phi} \\
&+\nabla \cdot\left[\left(\mu+\sigma_{\phi} \mu_{\mathrm{t}}\right) \nabla(\mathrm{kL})\right]
\end{aligned}
$$

The production of turbulent kinetic energy is stress-based, Eq. 3. and is limited in both the $\mathrm{k}$ and kL equations, Eq. 4.

$$
\begin{aligned}
\mathrm{P} & =\tau_{i j} \frac{\partial u_{i}}{\partial x_{j}}, \quad \tau_{i j}=2 \mu_{\mathrm{t}}\left(\mathrm{S}_{i j}-\frac{1}{3} \operatorname{tr}\{\boldsymbol{S}\} \delta_{i j}\right)-\frac{2}{3} \rho \mathrm{k} \delta_{i j}, \quad \mathrm{~S}_{i j}=\frac{1}{2}\left(\frac{\partial u_{i}}{\partial x_{j}}+\frac{\partial u_{j}}{\partial x_{i}}\right) \\
\mathrm{P}_{\mathrm{k}} & =\min \left(\mathrm{P}, 20 \mathrm{C}_{\mu}^{3 / 4} \frac{\rho \mathrm{k}^{5 / 2}}{(\mathrm{~kL})}\right)
\end{aligned}
$$

with the turbulent eddy viscosity computed using Eq. 5 .

$$
\mu_{\mathrm{t}}=\mathrm{C}_{\mu}{ }^{1 / 4} \frac{\rho(\mathrm{kL})}{\mathrm{k}^{1 / 2}}
$$

The functions are:

$$
\begin{aligned}
\mathrm{C}_{\mathrm{k}} & =\mathrm{C}_{\mu}^{3 / 4}, \quad \mathrm{C}_{\phi_{1}}=\zeta_{1}-\zeta_{2}\left(\frac{(\mathrm{kL})}{\mathrm{kL}_{v k}}\right)^{2}, \quad \mathrm{C}_{\phi_{2}}=\zeta_{3} \\
f_{\Phi} & =\frac{1+\mathrm{C}_{d 1} \xi}{1+\xi^{4}}, \quad \xi=\frac{\rho \sqrt{0.3 \mathrm{k}} \mathrm{d}}{20 \mu} \\
\mathrm{L}_{v k} & =\kappa\left|\frac{\mathrm{U}^{\prime}}{\mathrm{U}^{\prime \prime}}\right|, \quad \mathrm{U}^{\prime}=\sqrt{2 \mathrm{~S}_{i j} \mathrm{~S}_{i j}}, \quad \mathrm{U}^{\prime \prime}=\sqrt{\frac{\partial^{2} \mathrm{u}_{i}}{\partial x_{k}^{2}} \frac{\partial^{2} \mathrm{u}_{i}}{\partial x_{j}^{2}}}
\end{aligned}
$$


The second derivative expression of the velocity can be written out as:

$$
\mathrm{U}^{\prime \prime}=\sqrt{\left(\frac{\partial^{2} u}{\partial x^{2}}+\frac{\partial^{2} u}{\partial y^{2}}+\frac{\partial^{2} u}{\partial z^{2}}\right)^{2}+\left(\frac{\partial^{2} v}{\partial x^{2}}+\frac{\partial^{2} v}{\partial y^{2}}+\frac{\partial^{2} v}{\partial z^{2}}\right)^{2}+\left(\frac{\partial^{2} w}{\partial x^{2}}+\frac{\partial^{2} w}{\partial y^{2}}+\frac{\partial^{2} w}{\partial z^{2}}\right)^{2}}
$$

A limiter is applied on $\mathrm{L}_{v k}$,

$$
\begin{aligned}
\mathrm{L}_{v k, \min } & \leq \mathrm{L}_{v k} \leq \mathrm{L}_{v k, \text { max }}, \quad \mathrm{L}_{v k, \min }=\frac{(\mathrm{kL})}{\mathrm{kC}_{11}}, \quad \mathrm{~L}_{v k, \max }=\mathrm{C}_{12} \kappa \mathrm{d} f_{\mathrm{p}} \\
f_{\mathrm{p}} & =\min \left[\max \left(\frac{\mathrm{P}_{\mathrm{k}}(\mathrm{kL})}{\mathrm{C}^{3 / 4} \rho \mathrm{k}^{5 / 2}}, 0.5\right), 1.0\right]
\end{aligned}
$$

The boundary conditions for the two turbulence variables $\mathrm{k}$ and $(\mathrm{kL})$ along solid walls and recommended farfield boundary conditions for most applications are:

$$
\mathrm{k}_{\mathrm{wall}}=(\mathrm{kL})_{\mathrm{wall}}=0, \quad \mathrm{k}_{\infty}=9 \times 10^{-10} \mathrm{a}_{\infty}^{2}, \quad(\mathrm{~kL})_{\infty}=1.5589 \times 10^{-6} \frac{\mu_{\infty} \mathrm{a}_{\infty}}{\rho_{\infty}}
$$

where a represents the speed of sound. The constants are:

$$
\begin{aligned}
\sigma_{\mathrm{k}} & =1.0, \quad \sigma_{(\mathrm{kL})}=1.0 \\
\kappa & =0.41, \quad \mathrm{C}_{\mu}=0.09 \\
\zeta_{1} & =1.2, \quad \zeta_{2}=0.97, \quad \zeta_{3}=0.13 \\
\mathrm{C}_{11} & =10.0, \quad \mathrm{C}_{12}=1.3, \quad \mathrm{C}_{\mathrm{d} 1}=4.7
\end{aligned}
$$

\subsection{Jet Corrections for Free Shear and Compressibility}

Subsonic and supersonic jet flows are quite difficult to predict with most RANS turbulence models. For subsonic jets, turbulence models do not predict the correct mixing rate and predict core lengths that are either too long or too short. The base k-kL-MEAH2015 model also predicts too short of core length.

However, it turns out that the k-kL-MEAH2015 model predicts the correct mixing rate and shorter core length. By modifying the k-equation diffusion coefficient, the core length is improved, using Eqs. 13 and 14.

$$
\begin{aligned}
& \sigma_{\mathrm{k}}=f_{2} \sigma_{\mathrm{k}_{1}}+\left(1-f_{2}\right) \sigma_{\mathrm{k}_{2}}, \quad \sigma_{\mathrm{k}_{1}}=1.0, \quad \sigma_{\mathrm{k}_{2}}=0.5 \\
& f_{2}=\tanh \left(\Gamma^{2}\right), \quad \Gamma=\max \left(2 \frac{\sqrt{\mathrm{k}}}{\mathrm{C}_{\mu} \omega \mathrm{d}}, \frac{500 \nu}{\mathrm{d}^{2} \omega}\right), \quad \omega=\frac{\mathrm{k}^{3 / 2}}{(\mathrm{~kL}) \mathrm{C}_{\mu}^{1 / 4}}
\end{aligned}
$$

This modification does not affect attached flow simulations and is active only in the wake or shear flow regions. This is similar to the approach used by Menter in the SST model to switch between $\mathrm{k}-\omega$ and $\mathrm{k}-\varepsilon$ via the $f_{2}$ function.

Most turbulence models fail to predict high-speed shear flow, as the mixing is much slower than subsonic flow. Compressibility correction is the approach used by most turbulence models to improve this deficiency. We propose to use an approach similar to Wilcox's compressibility with cut-off Mach number to activate the compressibility for supersonic flow and not affect subsonic shear flow, as listed in Eqs. 15 and 16.

$$
\begin{aligned}
\mathrm{C}_{\mathrm{k}} & =\mathrm{C}_{\mu}^{1 / 4}\left(1+f_{c}\right), \quad \mathrm{C}_{\phi 2}=\xi_{3}+2.5 \mathrm{C}_{\mu}^{3 / 4} f_{c} \\
f_{c} & =1.5\left(\mathrm{M}_{\mathrm{t}}^{2}-\mathrm{M}_{0}^{2}\right) \mathcal{H}\left[\mathrm{M}_{\mathrm{t}}^{2}-\mathrm{M}_{0}^{2}\right], \quad \mathrm{M}_{\mathrm{t}}=\sqrt{\frac{2 \mathrm{k}}{a^{2}}}, \quad \mathrm{M}_{0}=0.19
\end{aligned}
$$

This jet corrected model, including both free shear and compressibility correction terms, is termed k-kL-MEAH2015+J. 


\section{Computational Methods}

\subsection{CFL3D Code}

CFL3D [11] is a structured-grid upwind multi-zone CFD code that solves the generalized thin-layer or full Navier-Stokes equations. In the current study, the full viscous terms are used for all computations. CFL3D can use point-matched, patched, or overset grids and employs local time-step scaling, grid sequencing and multigrid to accelerate convergence to steady state. A time-accurate mode is available, and the code can employ low-Mach number preconditioning for accuracy in computing low-speed steady-state flows. CFL3D is a cell-centered finite-volume method. It uses third-order upwind-biased spatial differencing on the convective and pressure terms, and second-order differencing on the viscous terms; it is globally second-order accurate. Roe's flux difference-splitting method [12] is used to obtain fluxes at the cell faces. The solution is advanced in time with an implicit approximate factorization method. For each loosely coupled iteration, the mean flow equations are advanced in time with the eddy-viscosity fixed then the turbulence model is advanced in time with the mean flow solution fixed. A wide variety of turbulence models are available in the code, including linear eddy-viscosity and nonlinear models.

\subsection{Fun3D Code}

Fun3D is an unstructured three-dimensional, implicit, Navier-Stokes code. Roe's flux difference splitting [12] is used for the calculation of the explicit terms. Other available flux construction methods include HLLC [13], AUFS [14], and LDFSS [15]. The default method for calculation of the Jacobians is the flux function of van Leer [16], but the method by Roe and the HLLC, AUFS and LDFSS methods are also available. The use of flux limiters are mesh and flow dependent. Flux limiting options include MinMod [17] and methods by Barth and Jespersen [18] and Venkatakrishnan [19]. Other details regarding Fun3D can be found in Anderson and Bonhaus [20] and Anderson et al. [21], as well as in the extensive bibliography that is accessible at the Fun3D Web site, http://fun3d.larc.nasa.gov.

\section{Test Case Descriptions}

The five geometries used in the verification and validation of the turbulence model are described in sub-sections 4.1 through 4.6. Table 1 lists relevant aspects of the simulation for each case. The flat plate and planar shear flows are low speed with little, if any, compressibility effects. The transonic bump flow has both flow separation and re-attachment points. The jet flows display both low and high compressibility characteristics. Comparisons are made with historic, canonical data or experimental results where available.

Table 1. Test Cases.

\begin{tabular}{lcl}
\hline Geometry & Grid & Flow physics \\
\hline Flat plate & 2D & wall bounded, attached, steady \\
Planar shear & 2D & free shear, steady \\
Transonic bump & Axisymmetric & wall bounded, separated, unsteady \\
Subsonic jet & Axisymmetric & free shear, low speed \\
Supersonic jet & Axisymmetric & free shear, compressible \\
\hline
\end{tabular}




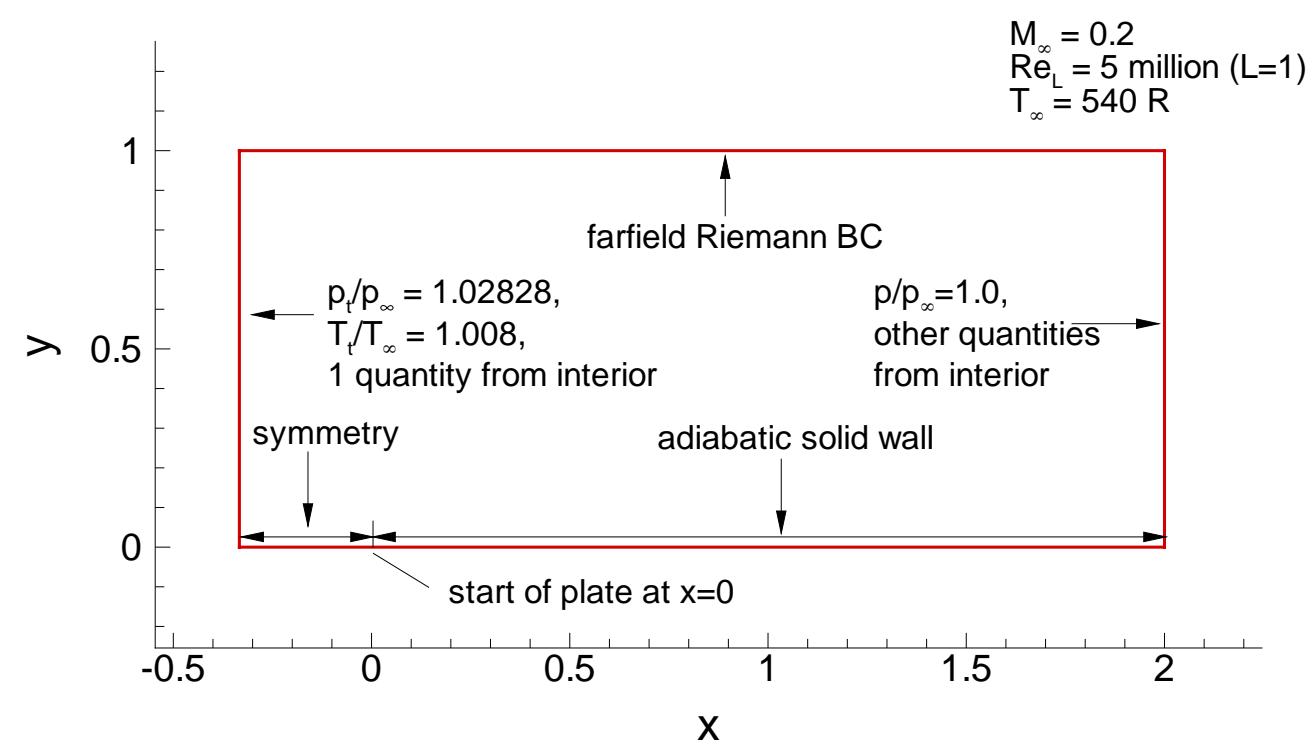

Figure 1. Flat plate geometry and boundary conditions.

\subsection{Zero Pressure Gradient Flat Plate}

Five successively refined grid levels are used to determine the numerical discretization error and the results from both codes are expected to converge to similar values. Different flow and turbulent quantities from each code are compared to additionally verify the implementation, along with available theoretical and experimental data.

Figure 1 shows the sketch of the flat plate test case with boundary conditions used in this analysis. This is a subsonic, $\mathrm{M}_{\infty}=0.2$ case at $\mathrm{Re}=5$ million per unit length. This is a verification and validation case. The following plot in Fig. 2 shows the convergence of the wall skin friction coefficient at $\mathrm{x}=0.97$ using five levels of grid size with the $\mathrm{k}-\mathrm{kL}$ turbulence model. Each coarser grid is exactly every-other-point of the next finer grid, ranging from the super fine grid of $(544 \times 384)$ cells to the very coarse grid of $(34 \times 24)$ cells. In the plot, the $\mathrm{x}$-axis is plotting $\sqrt{(1 / N)}$, which is proportional to grid spacing $(\mathrm{h})$. At the left of the plot, $\mathrm{h}=0$ represents an infinitely fine grid. The difference in the skin friction coefficient between the coarsest and finest grid is less than 0.0002. FUn3D and CFL3D converge toward the same result as the grid is refined.

The skin friction coefficient, using the k-kL turbulence model on the finest grid, ( 544 x 384 ) cells, over the entire plate, varies with respect to momentum thickness Reynolds number, as shown in Fig. 3. The results are computed using CFL3D and lie within the range of different correlation as compared with Karman-Schoenherr theory [22]. Using the finest grid results, Fig. 4 shows $\mathrm{u}^{+}$velocity with respect to $\mathrm{y}^{+}$predicted well compared with Cole's theory [23], and also within the range of different correlations. Turbulence kinetic energy, length scale (kL) and viscosity are other quantities used to validate the quality of turbulence model predictions. Figure 5 shows comparisons of the predicted turbulence quantities results from FUN3D and CFL3D codes. Results from the two codes on this grid are indistinguishable, with the exception of a very small differences close to the wall for the variable $\mathrm{kL}$. This could be the result of the difference in solver strategy. Fun3D is a node-centered code, whereas CFL3D is a cell-centered code. Figure 6 shows the comparisons between k-kL-MEAH2015 and SST-V turbulence models using CFL3D. Both models yield comparable results. 


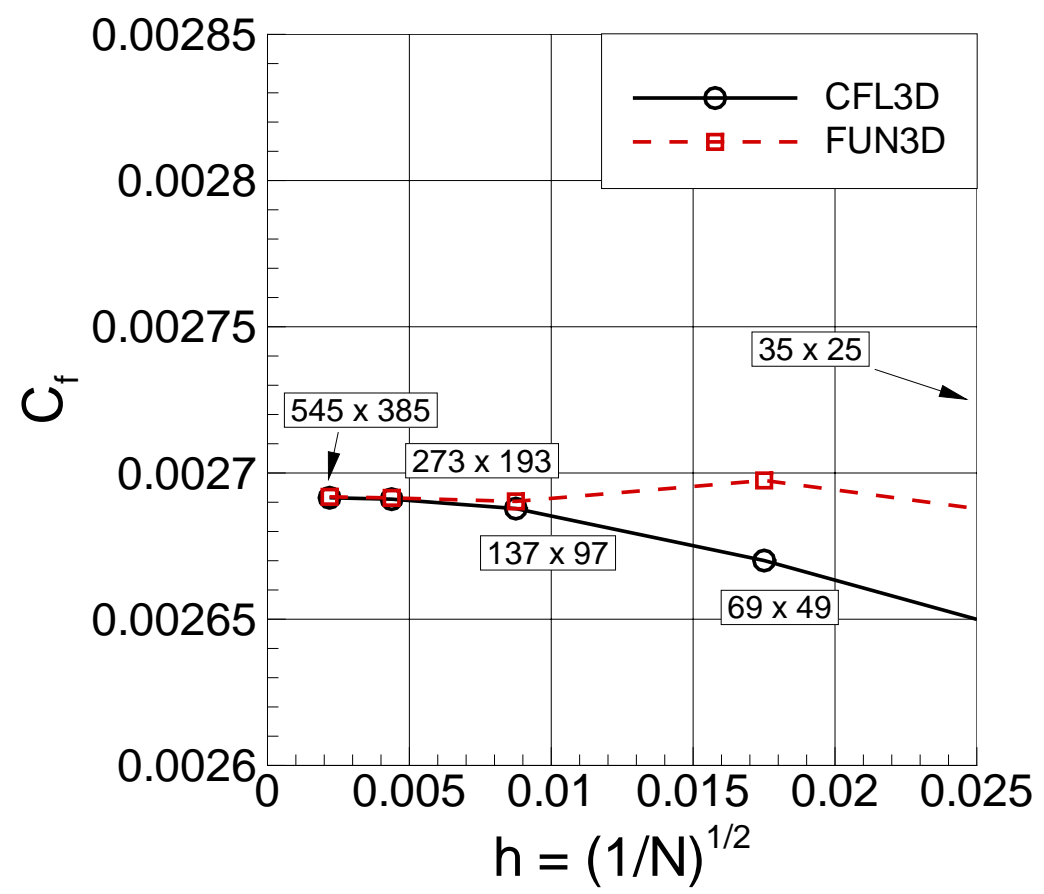

Figure 2. Skin friction coefficient with grid refinement, flat plate, $\mathrm{x}=0.97, \mathrm{M}_{\infty}=0.2$, $\mathrm{Re}_{\mathrm{L}}=5$ million, k-kL-MEAH2015.

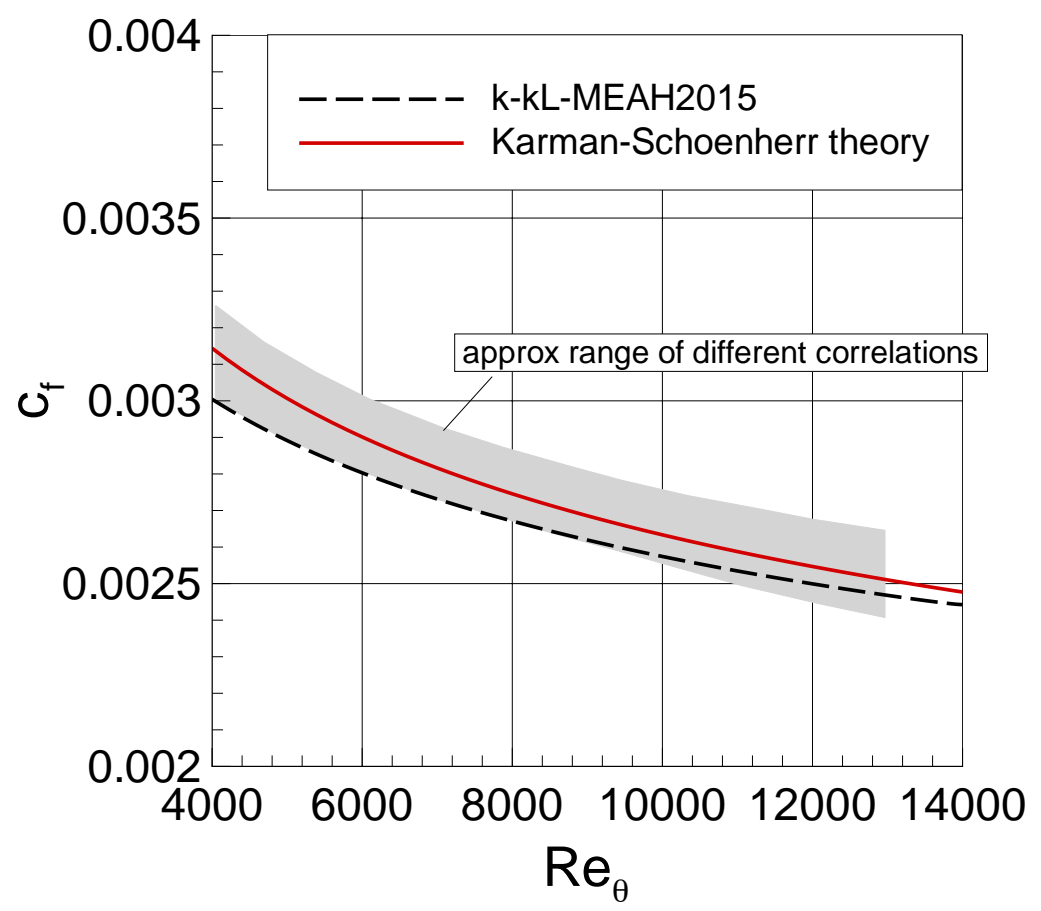

Figure 3. Skin friction correlation. - , Karman-Schoenherr [22]; -- k-kL-MEAH2015. 


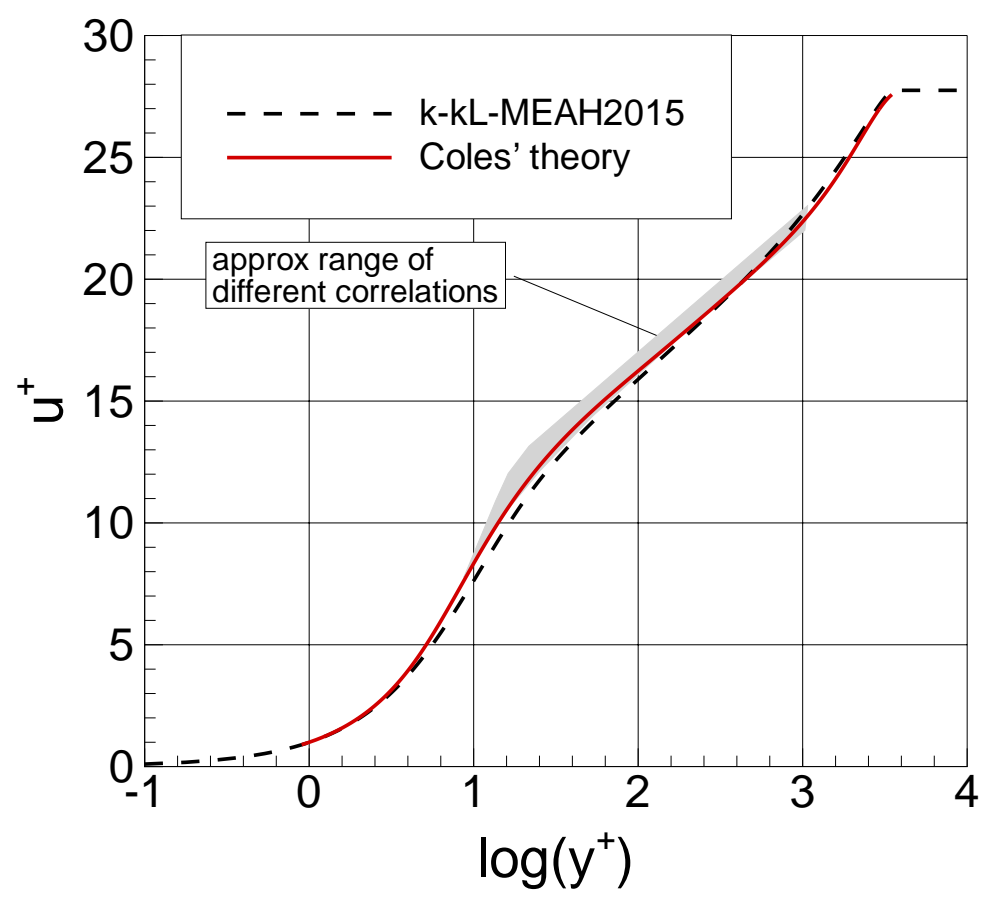

Figure 4. Velocity profile comparison of Cole's theory with k-kL turbulence model, $\operatorname{Re}_{\theta}=$ 10,000, Coles [23].

\subsection{Planar Shear}

The planar shear case focuses on the development of the free shear layer following the passing of two different streams over a thin plate. The smaller inner stream has Mach number near $\mathrm{M}=0.5$, whereas the outer larger stream has a Mach number near $\mathrm{M}=0.25$. The Reynolds number is $\operatorname{Re}_{\mathrm{L}}=50,000$ based on unit length of the grid $(\mathrm{L}=1)$. The computational domain extends from $-10<x<200$, and $0<y<100$. The separating plate extends from $-10<x<0$ at $y=0.5$. In terms of the plate, the reference length is 10 units. Both the lower and upper boundaries are taken to be symmetry planes. Figure 7 shows the close-up of the case with boundary conditions listed.

This is a verification case. The plot in Fig. 8 shows the convergence of the drag coefficient on the divided plate using five levels of grid size with the k-kL-MEAH2015 turbulence model. Each coarser grid is exactly every-other-point of the next finer grid, ranging from the super fine grid of three blocks ( $128 \times 256,128 \times 256,512 \times 512$ ) containing 327,680 cells to the very coarse grid of $(8 \times 16,8 \times 16,32 \times 32)$ containing 1280 cells. In the plot, the $\mathrm{x}$-axis plots $\sqrt{(1 / N)}$, which is proportional to grid spacing (h). The difference in the total skin friction coefficient comparing the coarsest and finest grid is less than 0.0002 .

Fun3D and CFL3D converge toward similar values as the grid is refined. Figure 9 shows comparisons of the predicted turbulence quantities results from FUN3D and CFL3D codes. Results from the two codes on the finest grid are essentially indistinguishable for $\mathrm{k}, \mathrm{kL}$ and turbulence viscosity. The fully developed turbulent shear flow exhibits self-similar behavior downstream. This can be achieved by normalizing the velocity and normal distance. The velocity can be normalized as $\left(u-u_{\mathrm{e}}\right) /\left(u_{\mathrm{m}}-u_{\mathrm{e}}\right)$, where $u_{\mathrm{e}}$ is the velocity at the edge of the outer stream, and $u_{\mathrm{m}}$ is the peak (centerline) velocity. When plotted against $\mathrm{y} / \mathrm{b}$, where $\mathrm{b}$ is the half width (location where $\left(u-u_{\mathrm{e}}\right)$ is half of $\left(u_{\mathrm{m}}-u_{\mathrm{e}}\right)$, the results can be compared 


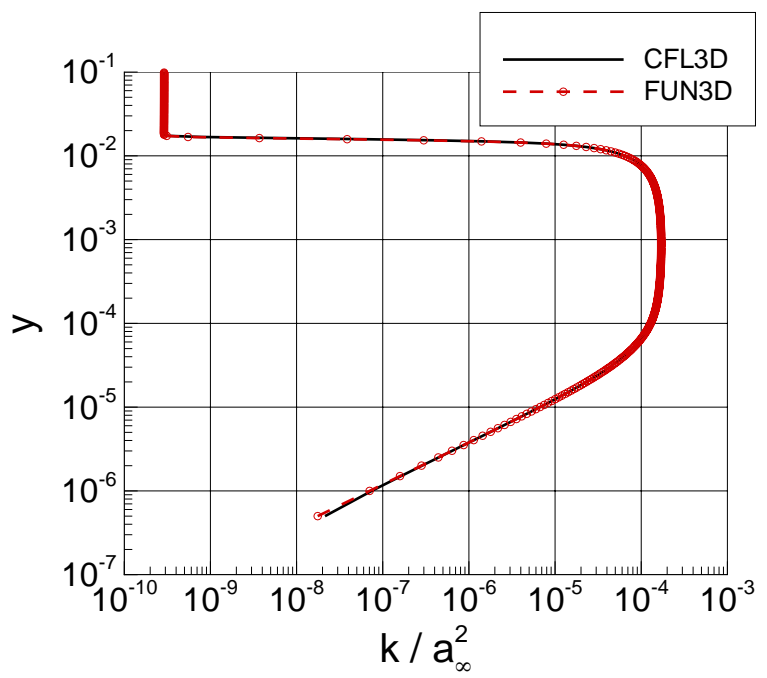

(a) Turbulent kinetic energy.

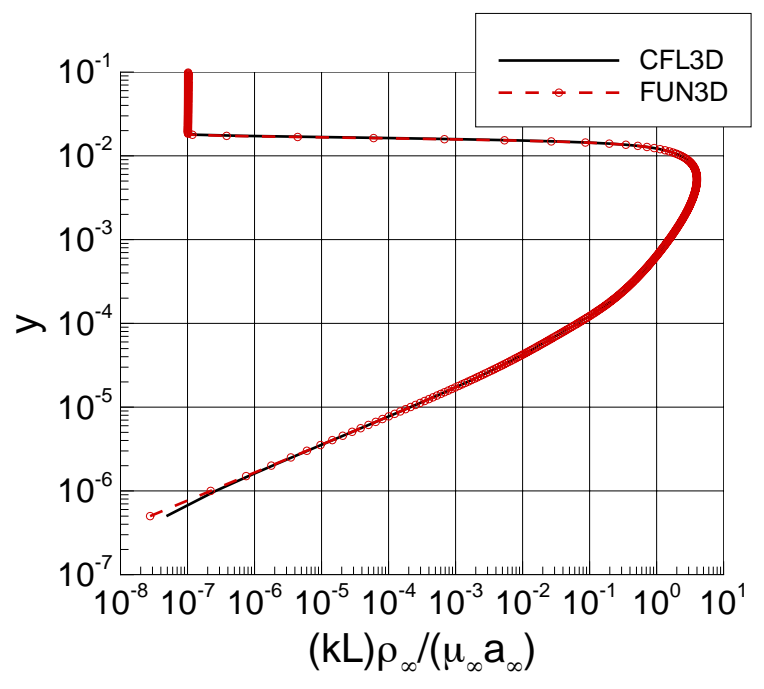

(b) kL.

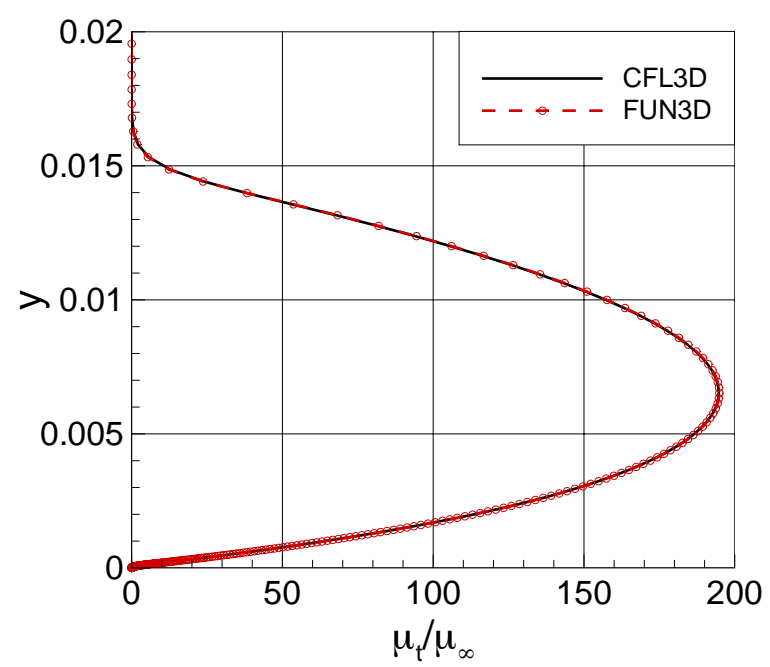

(c) Turbulent eddy viscosity.

Figure 5. Code-to-code comparison, flat plate, $\mathrm{M}_{\infty}=0.2, \mathrm{Re}_{\mathrm{L}}=5$ million, $\mathrm{x}=0.95$, $\mathrm{k}-\mathrm{kL}$ MEAH2015. 


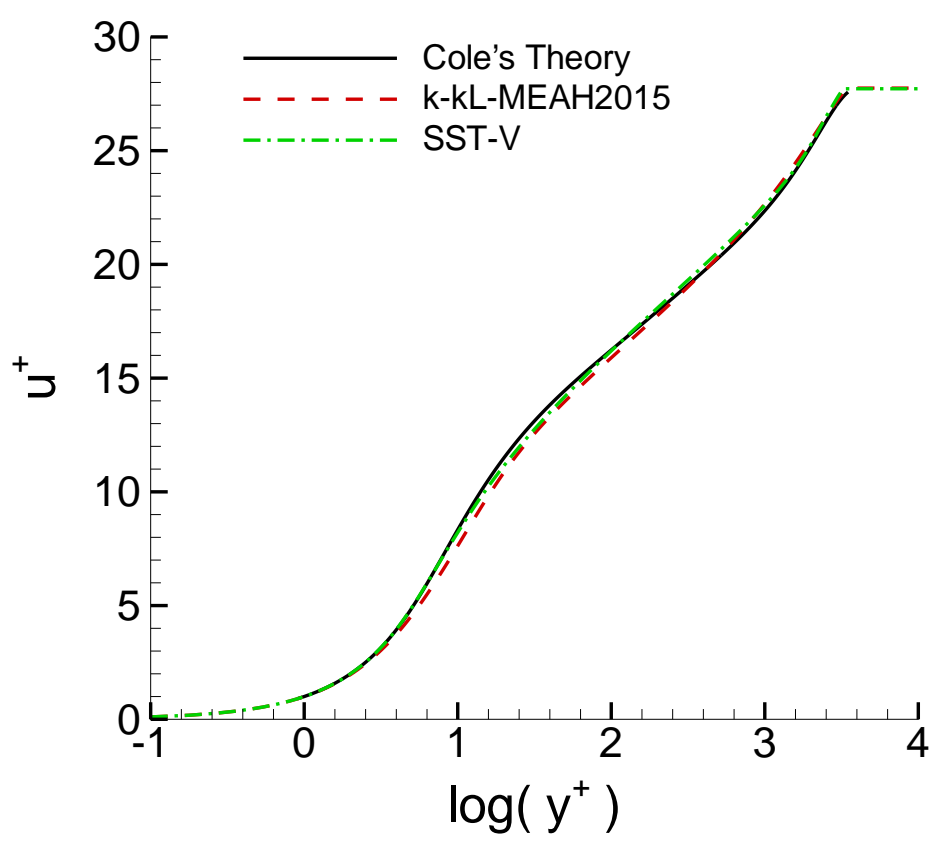

Figure 6. Comparison of velocity profiles, flat plate, $\mathrm{M}_{\infty}=0.2, \mathrm{Re}_{\mathrm{L}}=5$ million, $\mathrm{x}=0.97$.

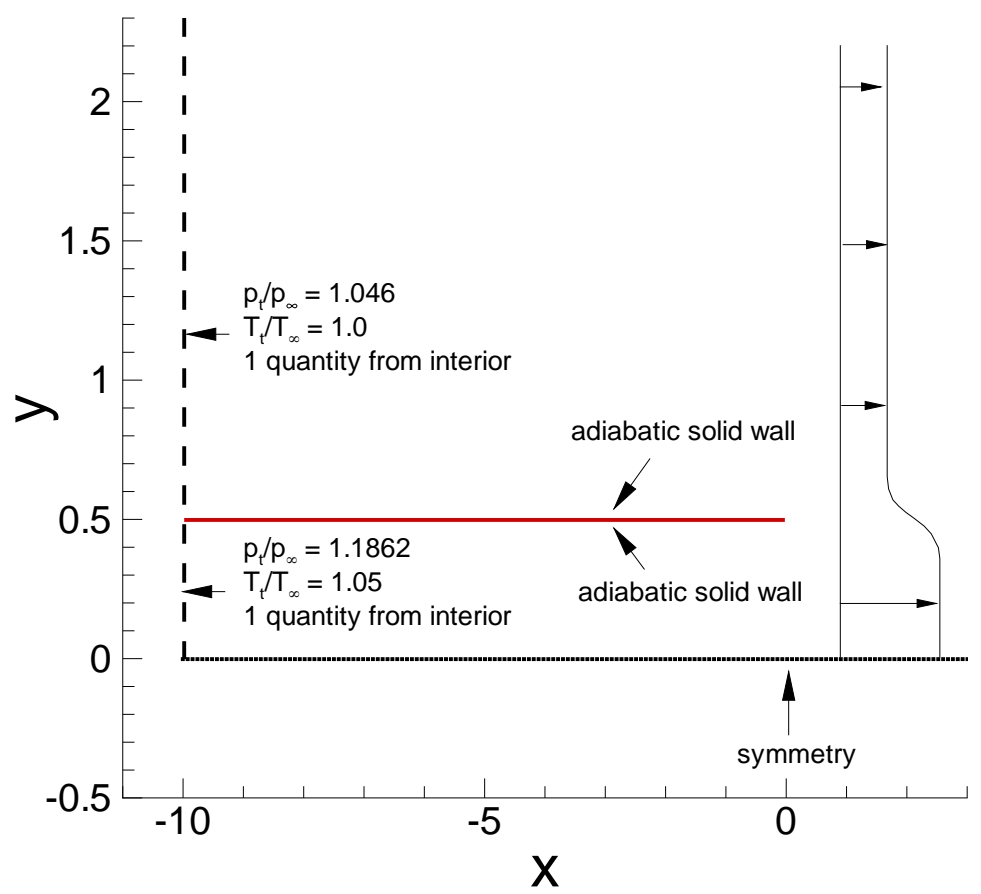

Figure 7. Sketch of geometry and boundary conditions. 


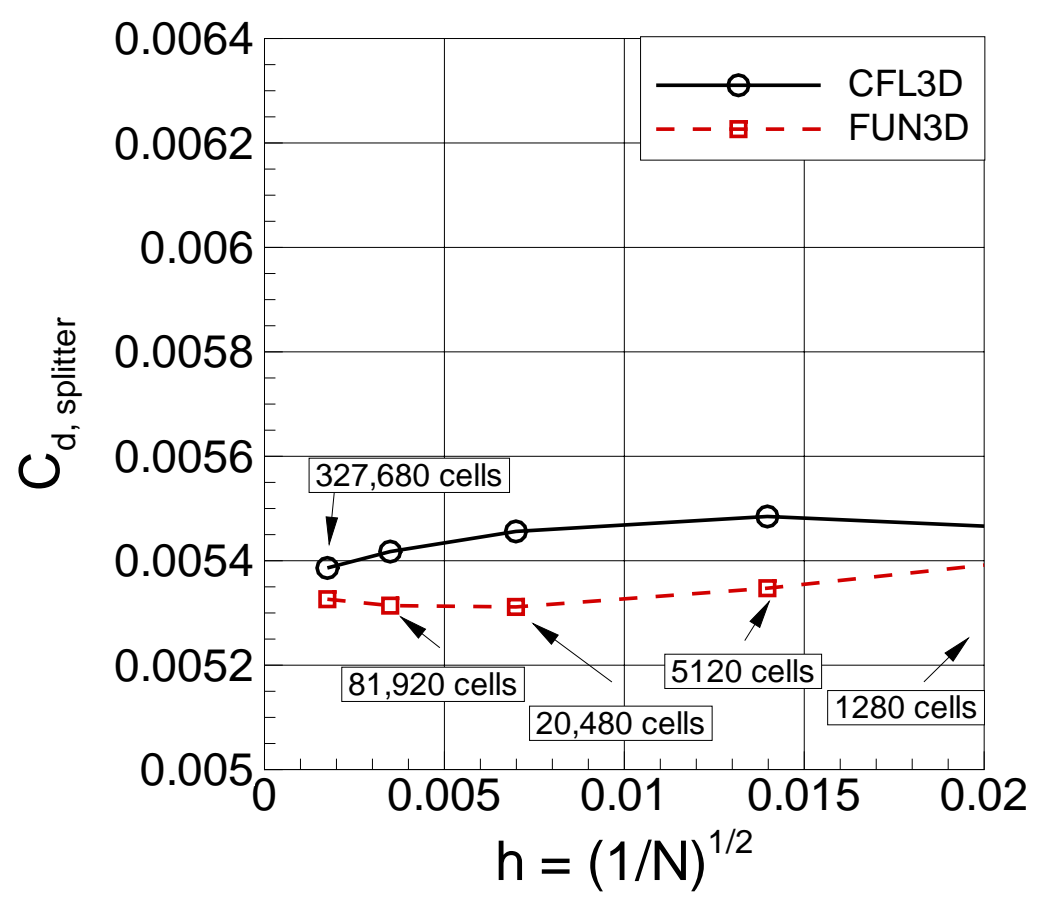

Figure 8. Effect of grid refinement on drag coefficient, planar shear, $\mathrm{M}_{\infty}=0.2, \mathrm{Re}_{\mathrm{L}}=$ 50,000, k-kL-MEAH2015.

to the experimental data of Bradbury and Riley [24]. In Fig. 10a, CFL3D results are taken from the three $\mathrm{x}$-locations $\mathrm{x}=29.2468, \mathrm{x}=64.2188$, and $\mathrm{x}=95.501$. The CFD results using the k-kL-MEAH2015 turbulence model are approximately self-similar, very tight, and agree well with the experiment. Similar comparisons are shown in Fig. 10b using SST-V, which did not agree as well with the data as k-kL-MEAH2015.

\subsection{Axisymmetric Transonic Bump}

Figure 11 shows the sketch of the axisymmetric transonic bump case with boundary conditions used in this analysis. This is a transonic, $\mathrm{M}_{\infty}=0.875$ case at $\mathrm{Re}_{\mathrm{L}}=2.763$ million based on $\mathrm{L}=$ chord length. The purpose here is to provide a validation case that establishes the model's ability to predict separated flow. For this particular axisymmetric transonic bump case, the experimental data are from Bachalo and Johnson [25]. The experiment utilized a cylinder of $0.152 \mathrm{~m}$ diameter in a closed return, variable density, and continuousrunning tunnel with $21 \%$ open porous-slotted upper and lower walls. The boundary layer incident on the bump was approximately $1 \mathrm{~cm}$ thick. The bump chord was $0.2032 \mathrm{~m}$. In the experimental case, with a freestream Mach number of 0.875 , the shock and trailing-edge adverse pressure gradient results in flow separation with subsequent reattached downstream of the bump. Figure 13 shows surface pressure and velocity as a function of $\mathrm{x}$, comparing experimental data and results from FUN3D and CFL3D using the k-kL-MEAH2015 turbulence model. Both CFD codes produced similar results. In general, surface pressure is in good agreement with data. The velocity distributions also agree well with experimental data for all the stations, and are generally better than the results generated using SST, shown in Fig. 12, especially at the $\mathrm{x} / \mathrm{c}=0.668$ location. The majority of RANS turbulence models fail to predict the correct reattachment of this separated flow case, with the separation bubble 


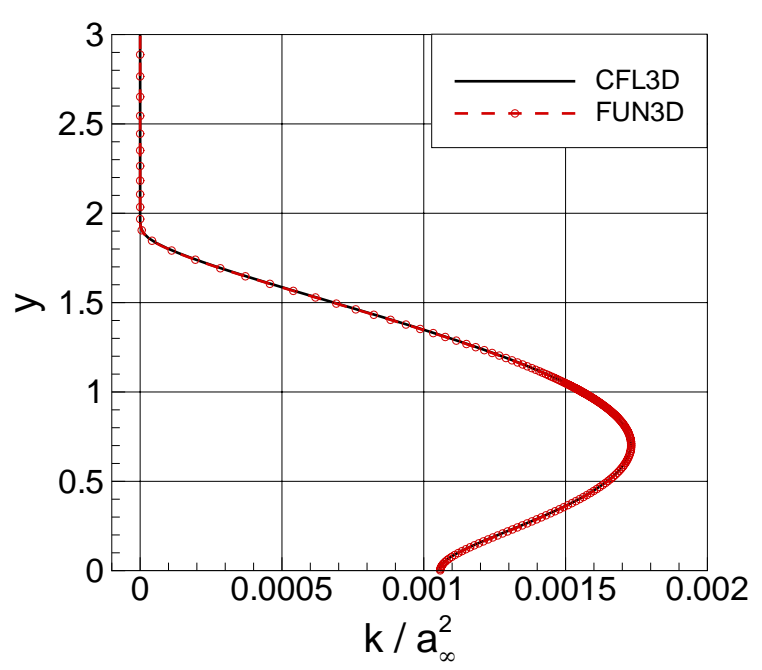

(a) Turbulent kinetic energy.

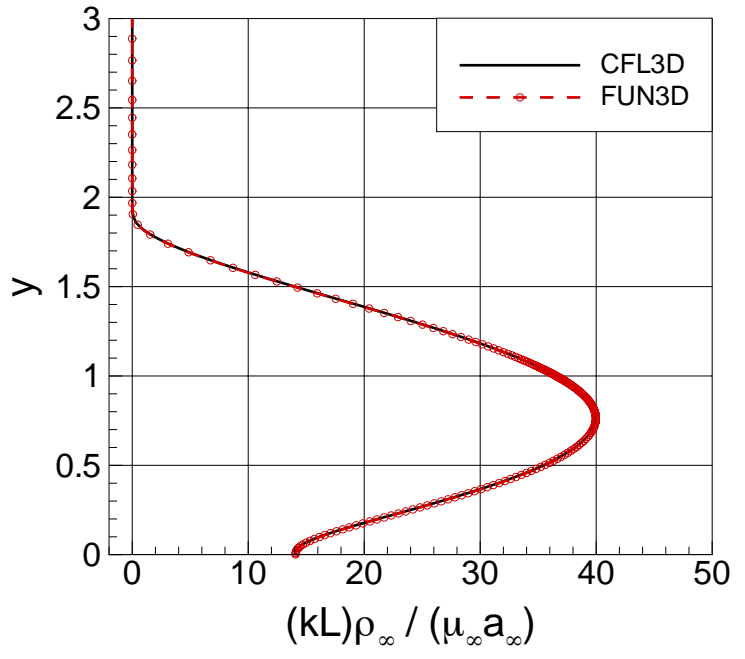

(b) $(\mathrm{kl})$.

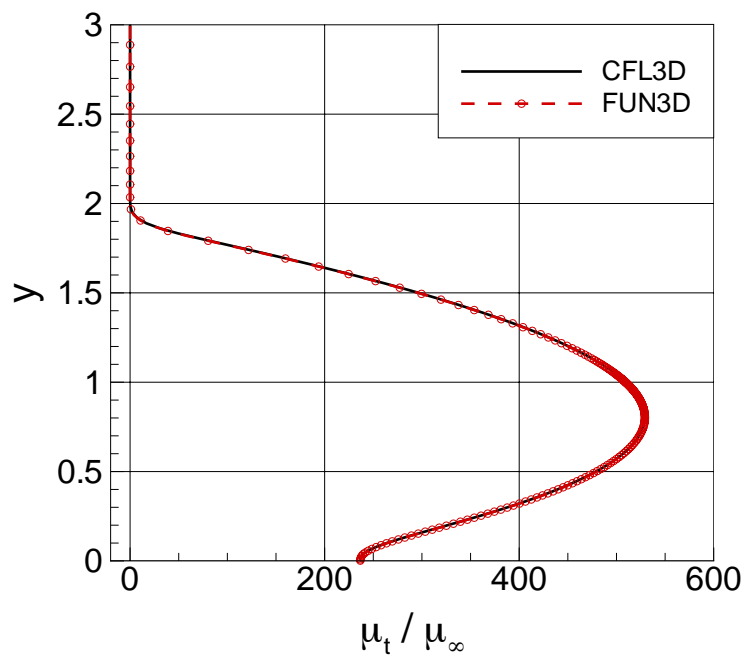

(c) Turbulent eddy viscosity.

Figure 9. Flow profiles, planar shear, $\mathrm{x}=29.2468, \mathrm{M}_{\infty}=0.2, \mathrm{Re}_{\mathrm{L}}=50,000, \mathrm{k}-\mathrm{kL}$ MEAH2015. 


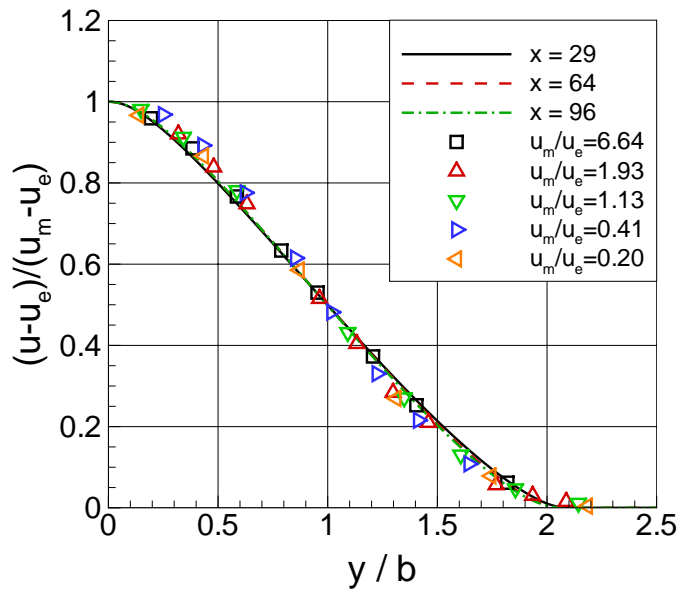

(a) k-kL turbulence model.

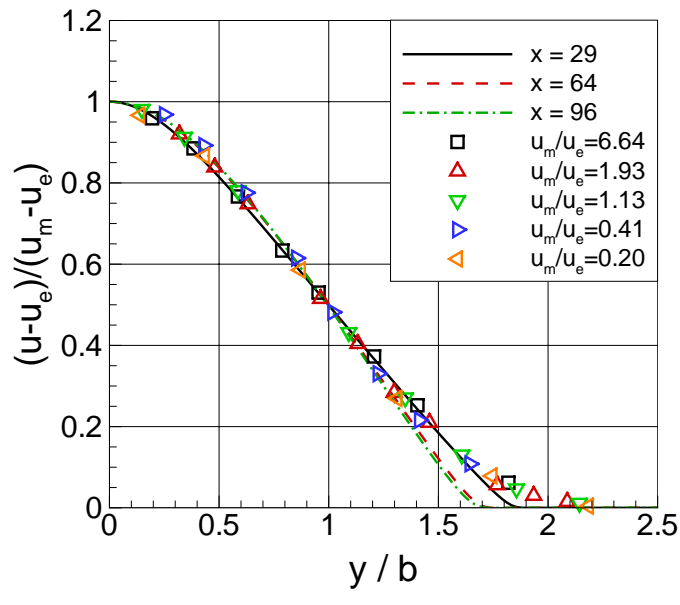

(b) SST-V turbulence model.

Figure 10. Self-similar velocity profiles, planar shear, $\mathrm{M}_{\infty}=0.2, \mathrm{Re}_{\mathrm{L}}=50,000$. symbols, Data-Bradbury \& Riley [24]; lines, $u_{\mathrm{m}} / u_{\mathrm{e}} \approx 0.5$, CFL3D, k-kL-MEAH2015.

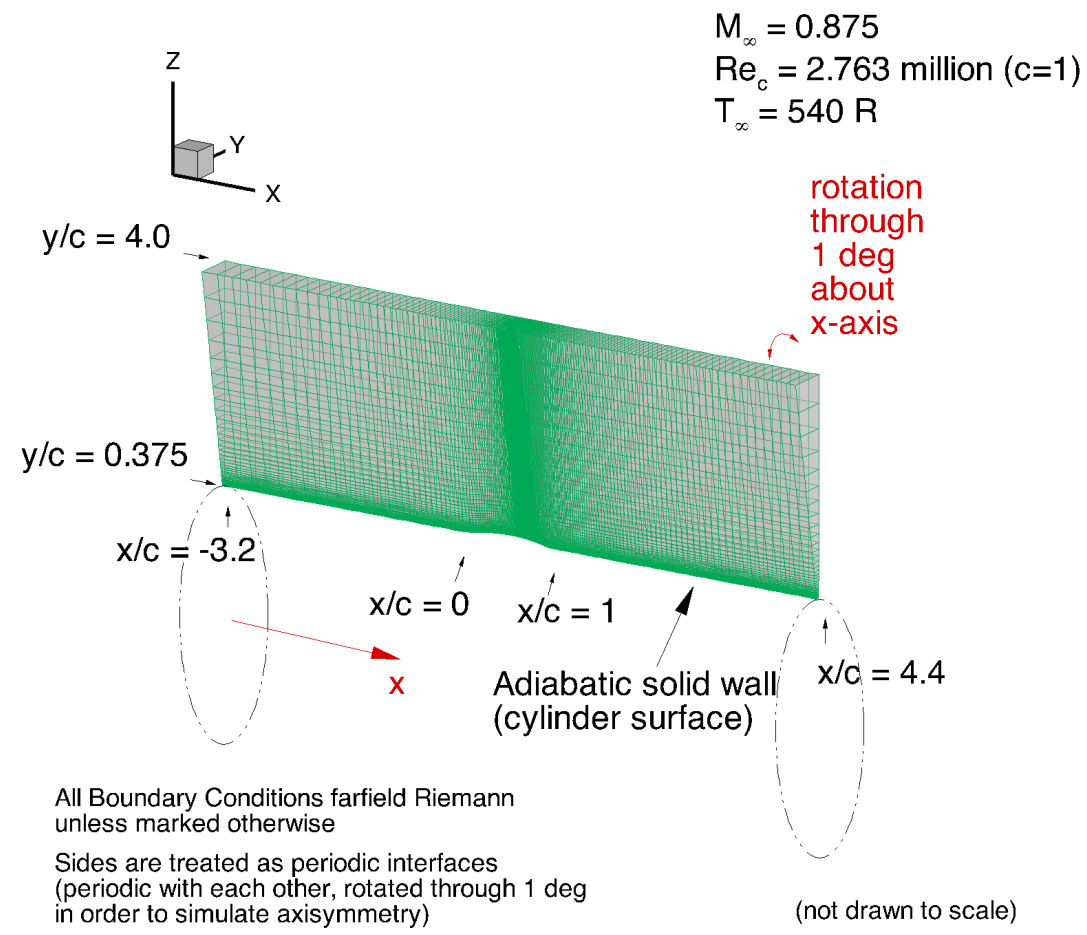

Figure 11. Sketch of transonic bump configuration. 


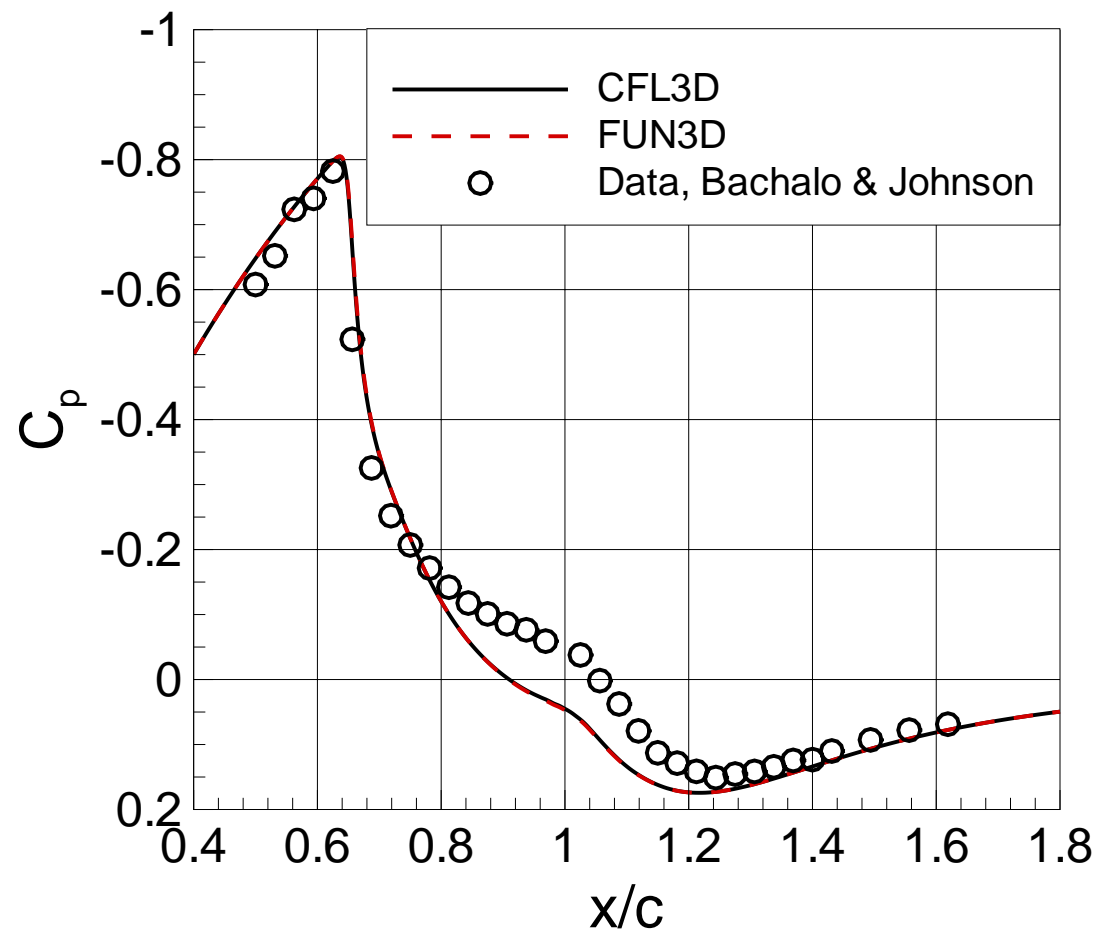

Figure 12. Comparison of surface static pressure coefficients, $\mathrm{M}_{\infty}=0.875$. symbols, DataBachalo \& Johnson [25]; lines, k-kl-MEAH2015.

size over predicted by at least $25 \%$.

The prediction of flow separation and reattachment location using k-kL-MEAH2015 and SST is tabulated in Table 2 . The bubble size predicted with k-kL-MEAH2015 is reduced to less than $8 \%$ compared with $27 \%$ from the SST simulation.

Table 2. Transonic bump.

\begin{tabular}{lccc}
\hline Data & Experiment & k-kL & SST \\
\hline Separation location & 0.70 & 0.68 & 0.65 \\
Reattachment location & 1.10 & 1.11 & 1.16 \\
Bubble size error $(\%)$ & - & 7.50 & 27.5 \\
\hline
\end{tabular}




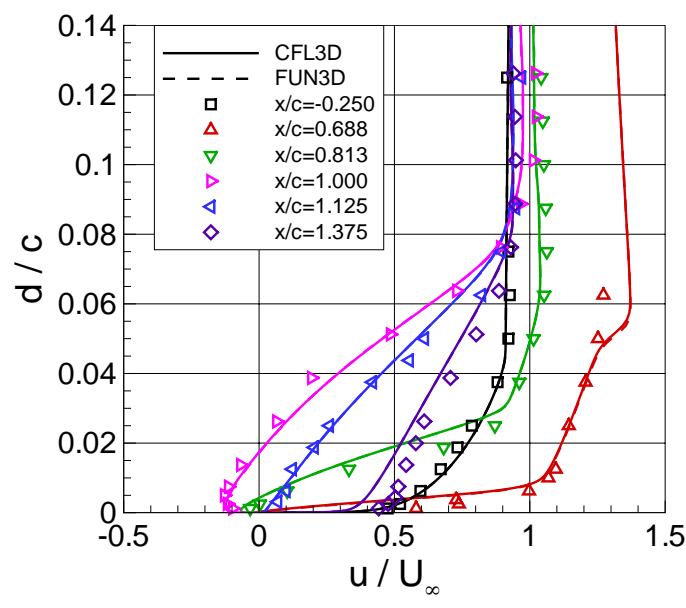

(a) k-kL-MEAH2015 turbulence model.

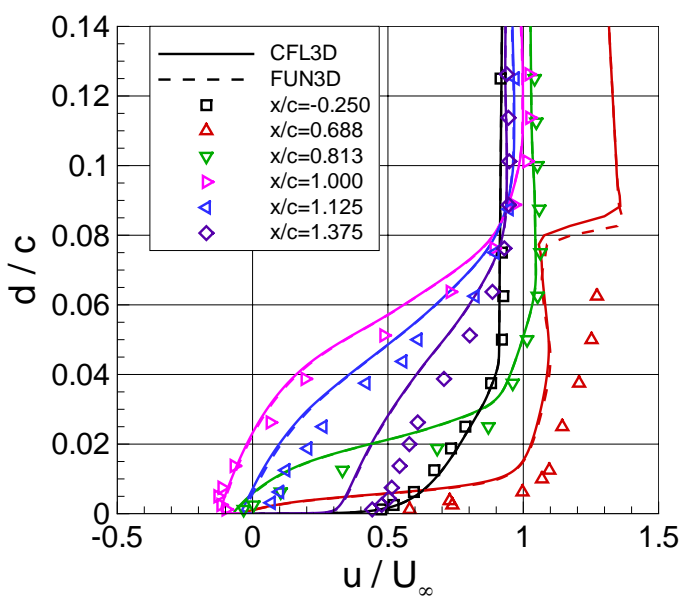

(b) SST turbulence model.

Figure 13. Velocity profile comparisons at $\mathrm{M}_{\infty}=0.875$ between Bachalo \& Johnson [25] (symbols) and CFD (lines).

\subsection{Subsonic Jet: Bridges}

Axisymmetric subsonic and near sonic jet cases are used to validate the prediction of jet flows. The experiment measured velocities as well as turbulence quantities downstream of the jet exit using Particle Image Velocimetry (PIV) [26]. Velocity profiles of interest are measured at the centerline $(\mathrm{y}=0)$ as well as other $\mathrm{x}$-locations. In the present report, we are comparing the turbulence model results with the centerline values for velocity data. The grid used was obtained from [9] and was converted to unstructured hex grid with 145,561 nodes, and solved only using the FUn3D code. In the experiment, the axisymmetric jet exits into quiescent (non-moving) air at two nozzle exit Mach conditions, $\mathrm{M}_{\text {exit,acoustic }}=$ $\mathrm{u}_{\mathrm{jet}} / \mathrm{a}_{\infty}=0.51$ and 0.9. However, because simulating flow into totally quiescent air is difficult to achieve for some CFD codes, here the solution is computed with a very low background ambient condition of $\mathrm{M}_{\infty}=0.01$, moving left-to-right in the same direction as the jet). Figure 14 shows the grid and flow setup for the subsonic jet case. The ability of the k-kL-MEAH2015-J turbulence model in predicting jet flow, compared with the basic k-kL-MEAH2015 and SST turbulence models, is shown in Figs. 15 and 16.

$$
\text { [h] }
$$

Table 3. Subsonic jet conditions.

\begin{tabular}{ccccc}
\hline Set Point & Mach $_{\text {exit,acoustic }}$ & NPR & NTR & $\mathrm{T}_{\text {jet,static }} / \mathrm{T}_{\infty}$ \\
\hline 3 & 0.51 & 1.197 & 1.0 & 0.950 \\
7 & 0.90 & 1.861 & 1.0 & 0.835 \\
\hline
\end{tabular}

For Set Point 3 in Fig. 15, the jet core length and rate of decay are better predicted when using the k-kL-MEAH2015+J model, as shown in Fig. 15a. In particular, the jet core length is in better agreement with experiment than the much longer core predicted using the SST turbulence model. Very good comparisons of k-kL-MEAH2015+J are shown in Fig. 15b for the velocity variations with radial direction at different $\mathrm{x}$ locations. Figure 16 shows results for Set Point 7. Again the k-kL-MEAH2015 +J turbulence model predicts the jet flow better than the basic k-kL-MEAH2015 and SST turbulence models. As shown in 


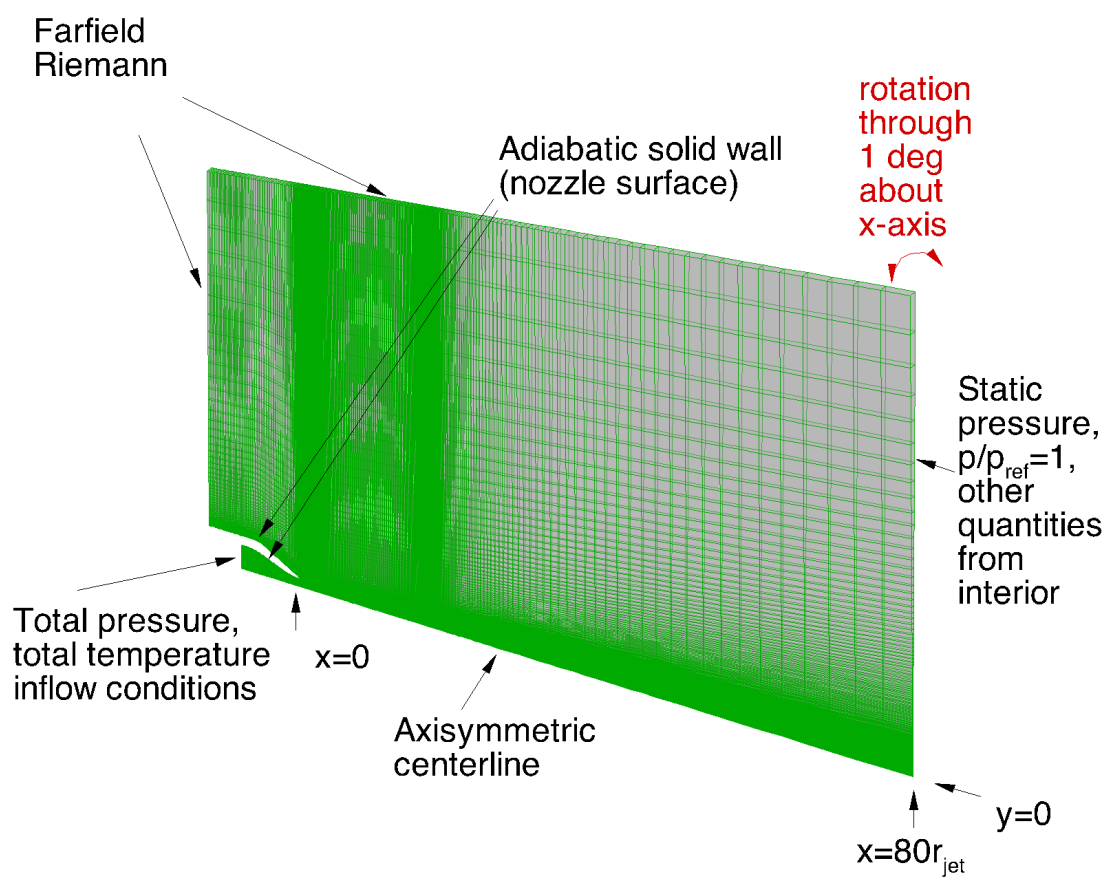

Figure 14. ARN1 geometry and boundary conditions.

Fig. 16a, the jet core length and rate of decay is in better agreement with experiment. Very good comparisons of k-kL-MEAH2015 $+\mathrm{J}$ are shown in Fig. 16b for the velocity variations with radial direction at different $\mathrm{x}$ locations.

\subsection{Supersonic Jet: Seiner}

In the subsonic jet cases above, the first part of the jet correction terms (free shear correction) improved the prediction of the k-kL-MEAH2015 turbulence model by shifting the jet core downstream. The results are in generally good agreement with experimental data and are better than SST predictions. The second part of the jet correction terms (compressibility correction) has no effect in either of the subsonic jet cases, because the turbulence Mach number is smaller than the cutoff at 0.19. The term will be activated around jet Mach number of 1.5 .

The supersonic jet cases, Seiner [27] and Eggers [28], are frequently used to validate turbulence models for high-speed flow. RANS models are generally not capable of predicting the mixing rate and core length of high-speed jet flow without adding a compressibility correction. Both cases are for nozzles operating near design condition and fully expanded. However, because flow into quiescent air is difficult to achieve for some CFD codes for such high shear flow cases, the simulations are run with low background ambient conditions of $\mathrm{M}_{\infty}=0.05$. Three grid levels are utilized to verify the implementation of the proposed modification and show grid convergence. The first case is Seiner's Mach 2.0 C-D nozzle operating at NPR $=7.824$. The grid was obtained from the NPARC website [29] and converted to an unstructured hex grid. The grid was modified to provide 3 grid levels 28433 , 112865 and 449729 nodes. The medium grid is shown in Fig. 17. These cases were run only using the Fun3D code. Figure 18 shows the grid effects on the prediction of centerline 


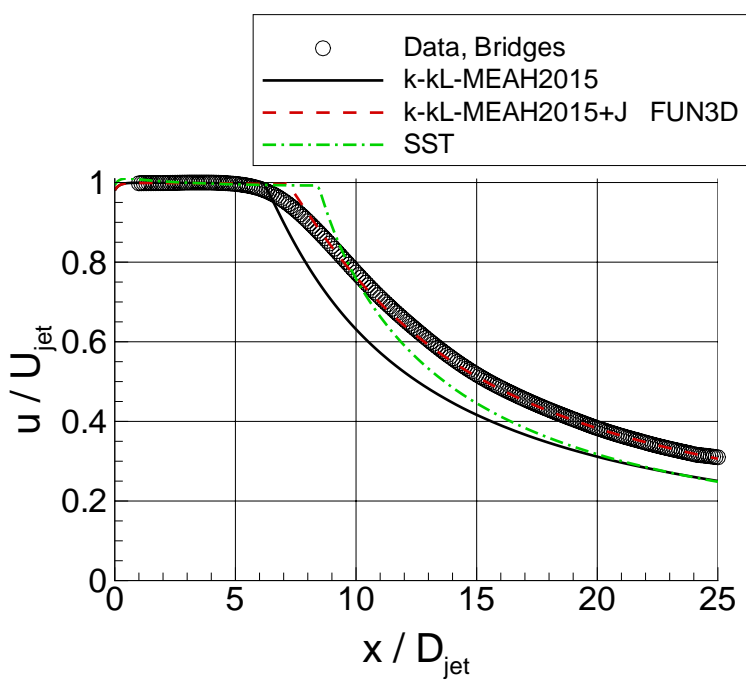

(a) Streamwise centerline velocity.

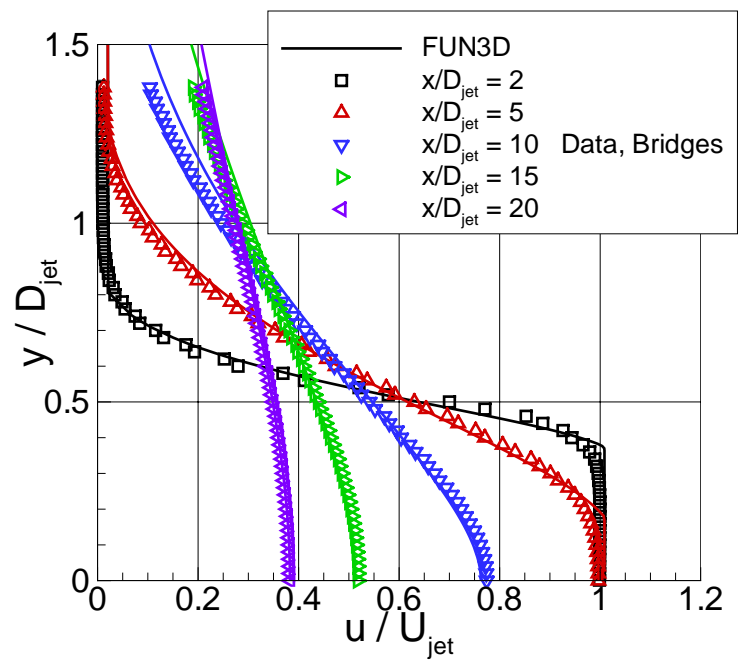

(b) Radial velocity profiles, k-kL-MEAH2015+J.

Figure 15. Comparison of jet velocity data, ARN1, Set Point 3. symbols, Data-Bridges [26]; lines, FUN3D.

Mach number and total pressure using k-kL-MEAH2015+J turbulence model. All threegrid levels give similar results and the difference is very small between the medium and fine grid levels. As shown in Fig. 19 using medium grids, both the basic k-kL-MEAH2015 and SST turbulence models underpredict the jet core length for centerline Mach number and total pressure. This behavior is observed when using many other RANS turbulence models. The k-kL-MEAH2015+J model improves the results dramatically and achieves very good agreement with experimental data.

\subsection{Supersonic Jet: Eggers}

The second case is Eggers' supersonic C-D nozzle test [28] and is sketched in Fig. 20. The grid was obtained from [30] and converted to unstructured hex grid. The nozzle geometry produces an exit Mach number of 2.2 when fully expanded and was set to the operating condition of NPR $=11.03$. The grid was modified to produce 3 grid levels consisting of 21432, 84563 and 335925, nodes each and all simulations were run with Fun3D. Figure 21 shows the grid effects on the prediction of centerline Mach number velocity variation at $\mathrm{x} / \mathrm{r}=28.93$ using $\mathrm{k}-\mathrm{kL}-\mathrm{MEAH} 2015+\mathrm{J}$ turbulence model. All three-grid levels give similar results and the difference is very small between the medium and fine grid levels. Using the medium grid, both the basic k-kL-MEAH2015 and SST turbulence models underpredict the jet core length as shown in Fig. 22 for centerline velocity. As seen in the previous section, the jet correction model with the baseline k-kL-MEAH2015 improves the comparison with the experimental results. Similarly, the k-kL-MEAH2015+J model produces better matching for the variations of axial velocity with radial direction at different $\mathrm{x}$ locations as shown in Fig. 23. 


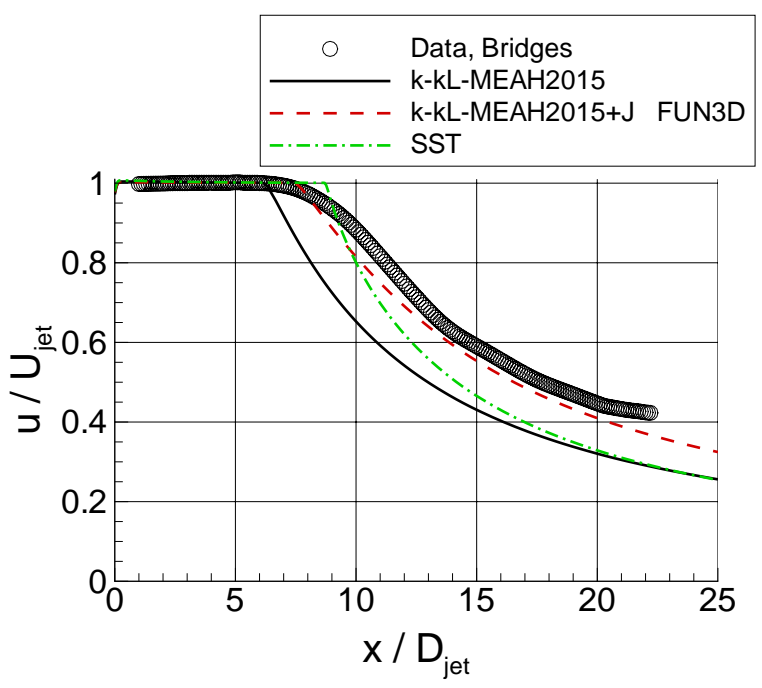

(a) Streamwise centerline velocity.

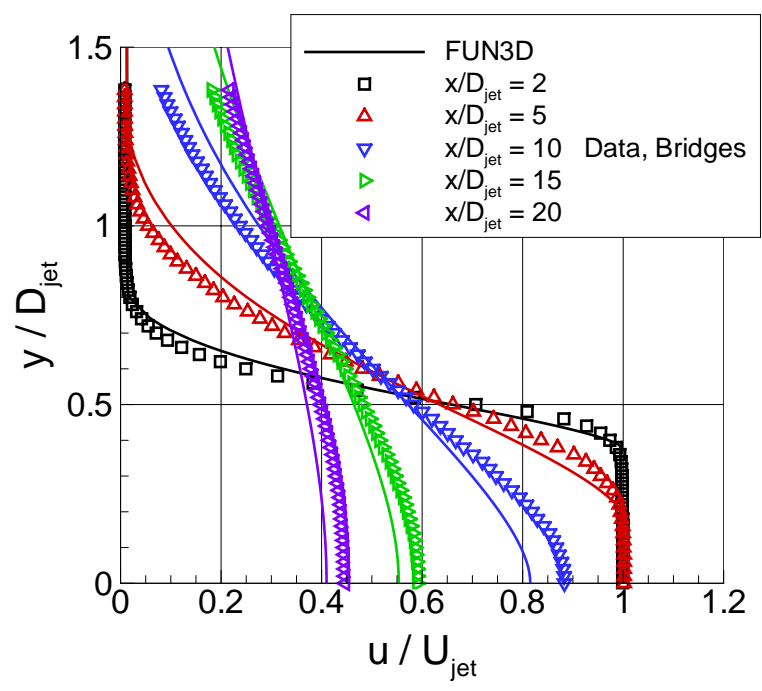

(b) Radial velocity profiles, k-kL-MEAH2015+J.

Figure 16. Comparison of jet velocity data, ARN1, Set Point 7. symbols, Data-Bridges [26]; lines, FUN3D.

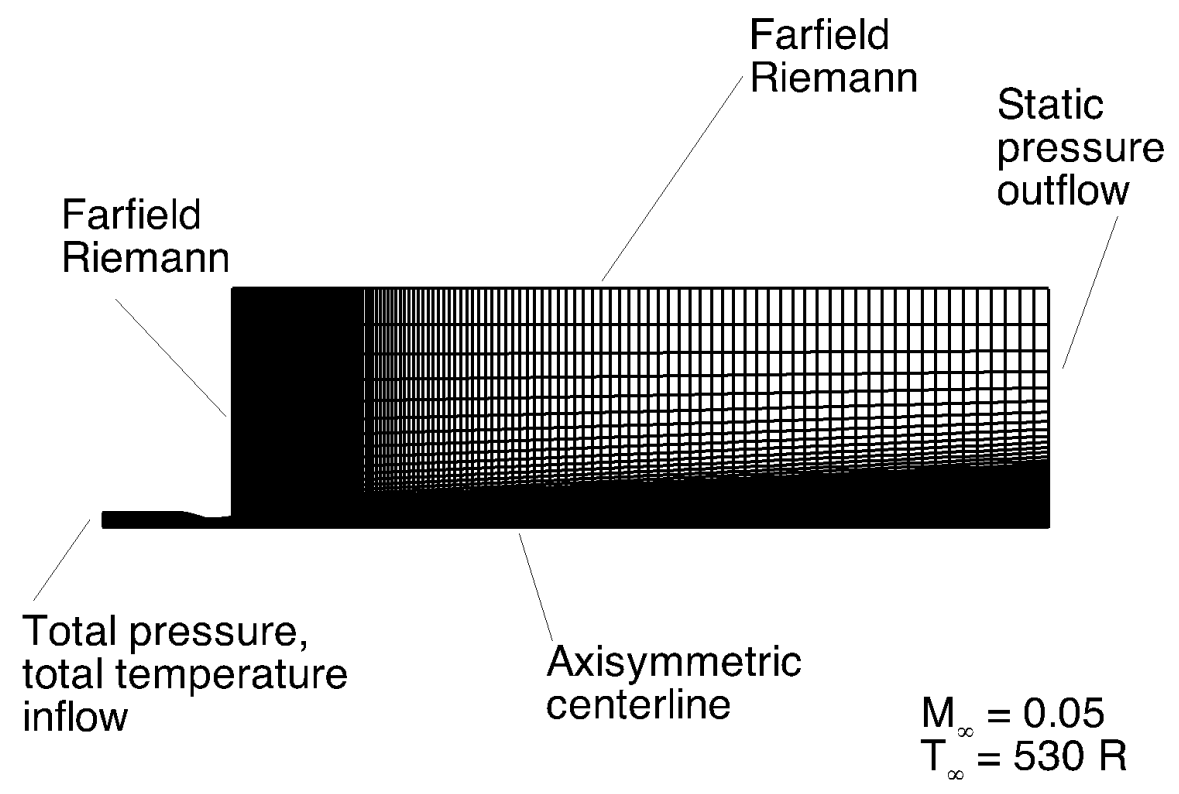

Figure 17. Axisymmetric nozzle geometry and conditions, Seiner [27]. 


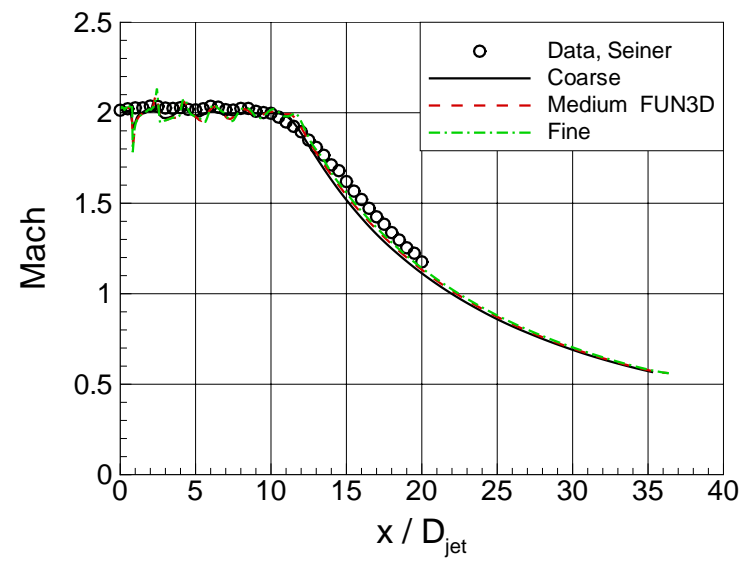

(a) Centerline Mach number.

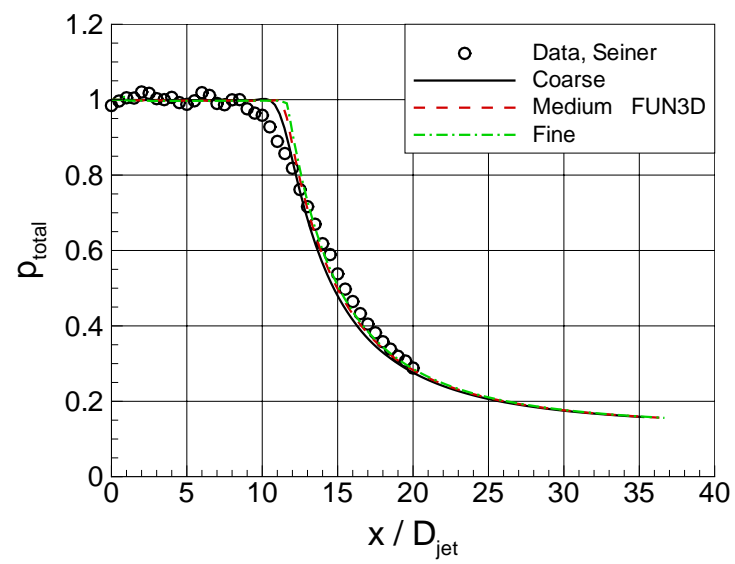

(b) Centerline total pressure.

Figure 18. Effect of grid refinement, NPR $=7.824$, Mach 2. jet. symbols, Data-Seiner [27]; lines, FUN3D, k-kL-MEAH2015+J.

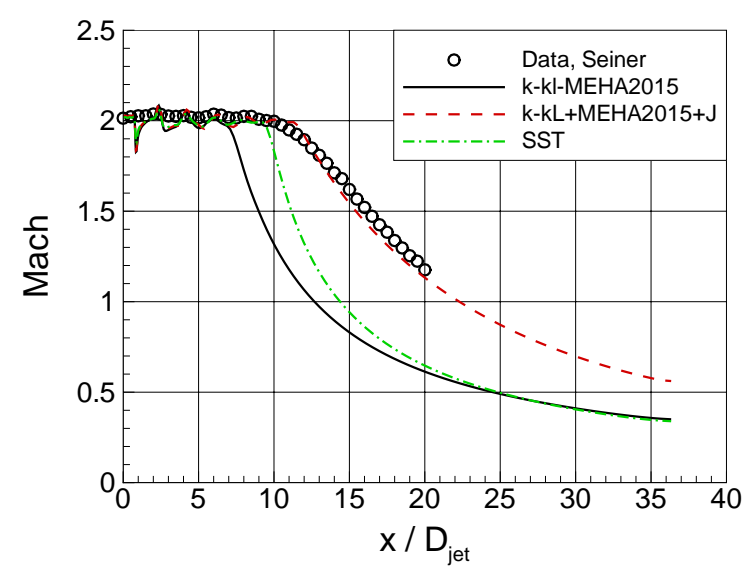

(a) Centerline Mach number.

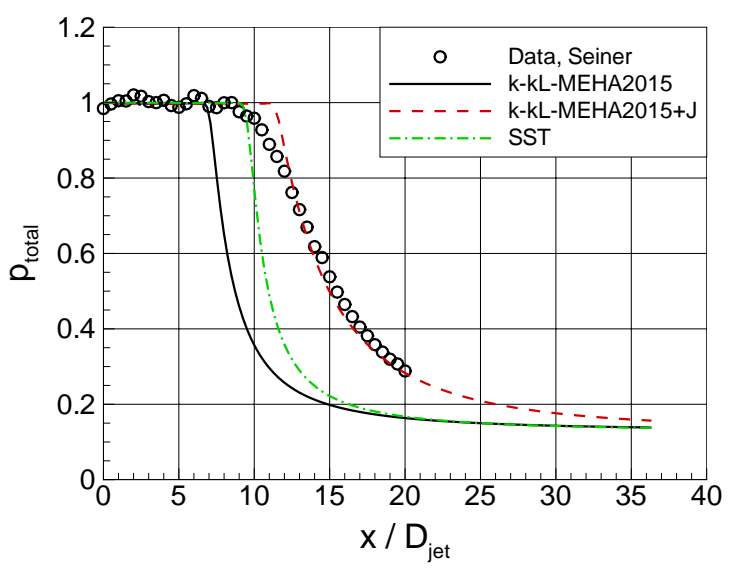

(b) Centerline total pressure.

Figure 19. Effect of jet correction on flowfield, NPR $=7.824$, Mach 2. jet. symbols, Data-Seiner [27]; lines, FUN3D. 


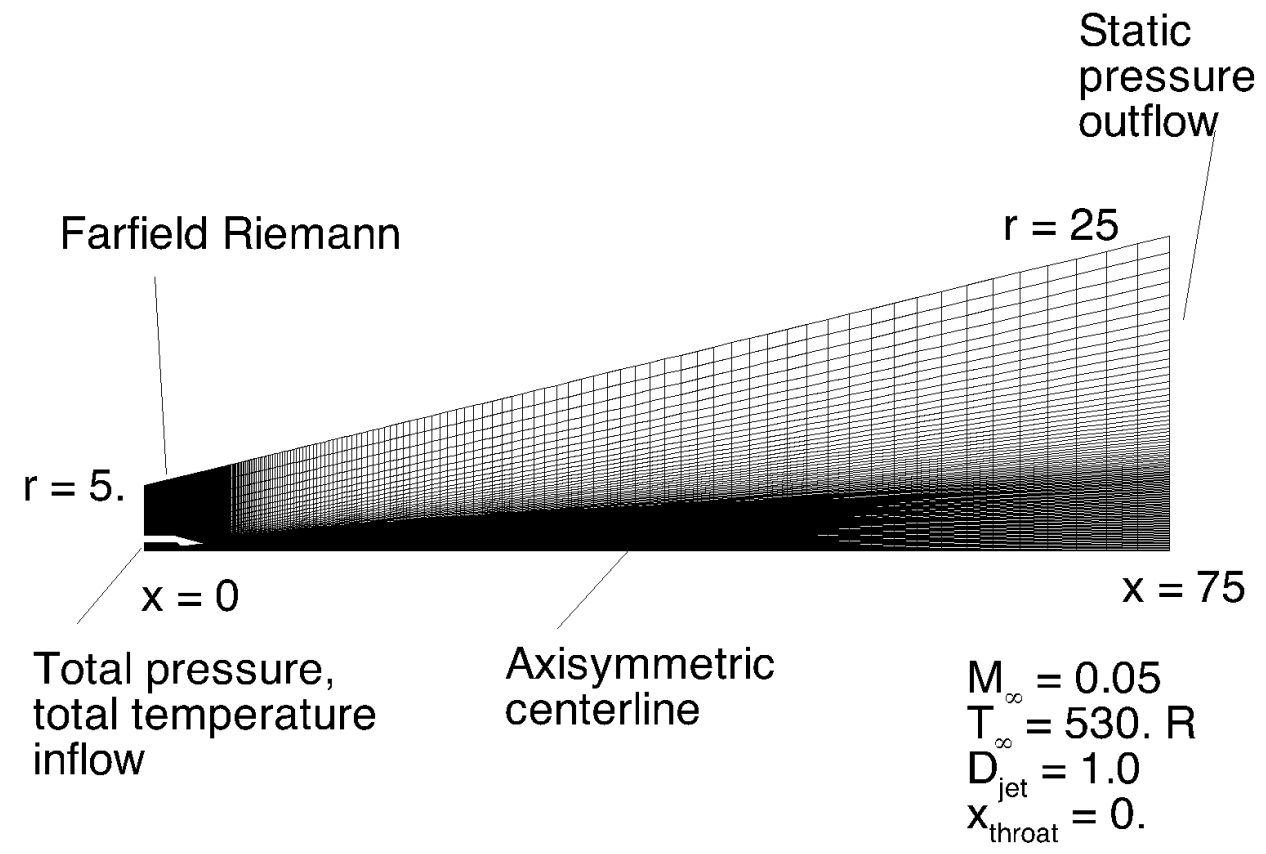

Figure 20. Geometry and boundary conditions, Eggers [28].

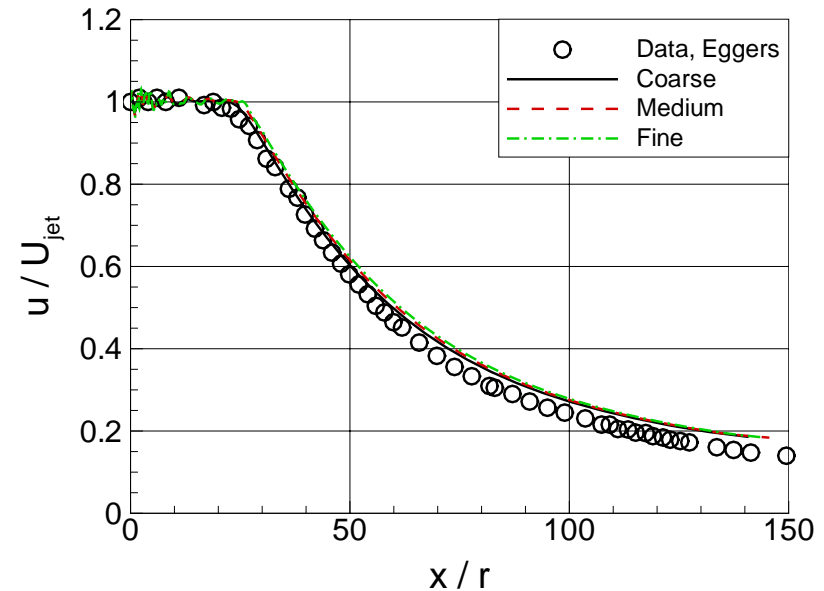

(a) Streamwise centerline velocity.

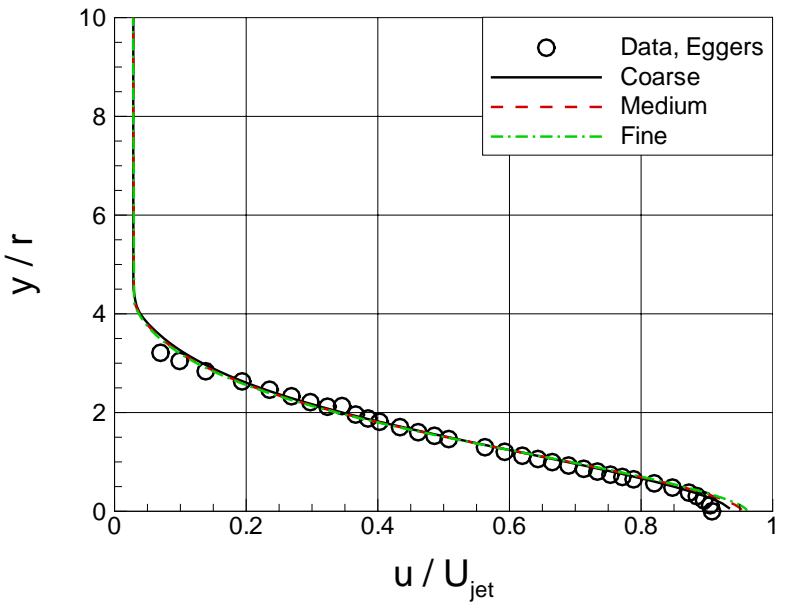

(b) Radial velocity profile.

Figure 21. Effect of grid refinement on velocities, Mach 2. jet. symbols, Data-Eggers [28]; lines, FUN3D, k-kL-MEAH2015+J. 


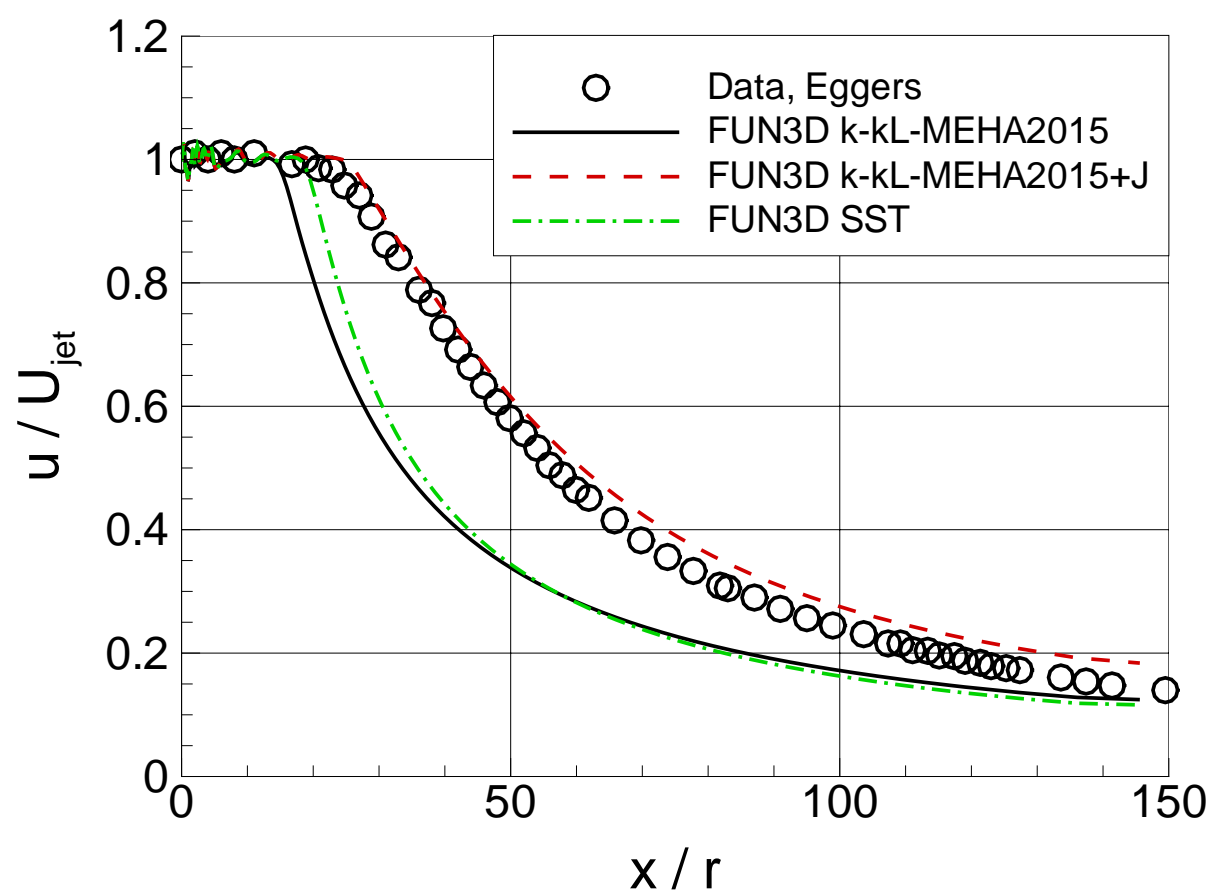

Figure 22. Effect of jet correction on centerline velocity, Mach 2. jet. symbols, DataEggers [28]; lines, FUN3D. 


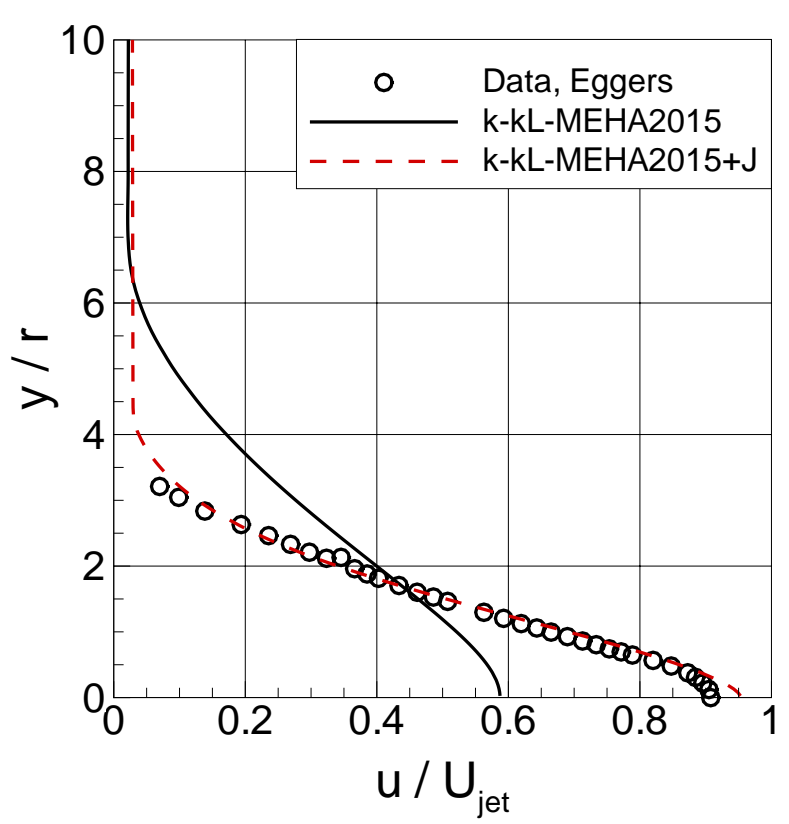

(a) $\mathrm{x} / \mathrm{r}=28.93$.

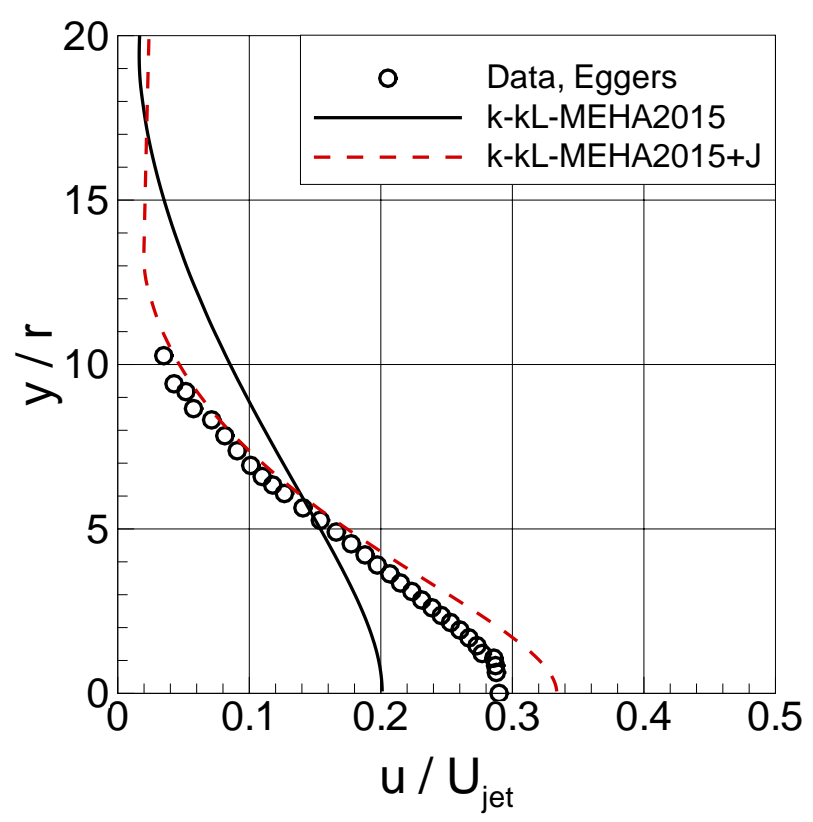

(c) $\mathrm{x} / \mathrm{r}=89.90$.

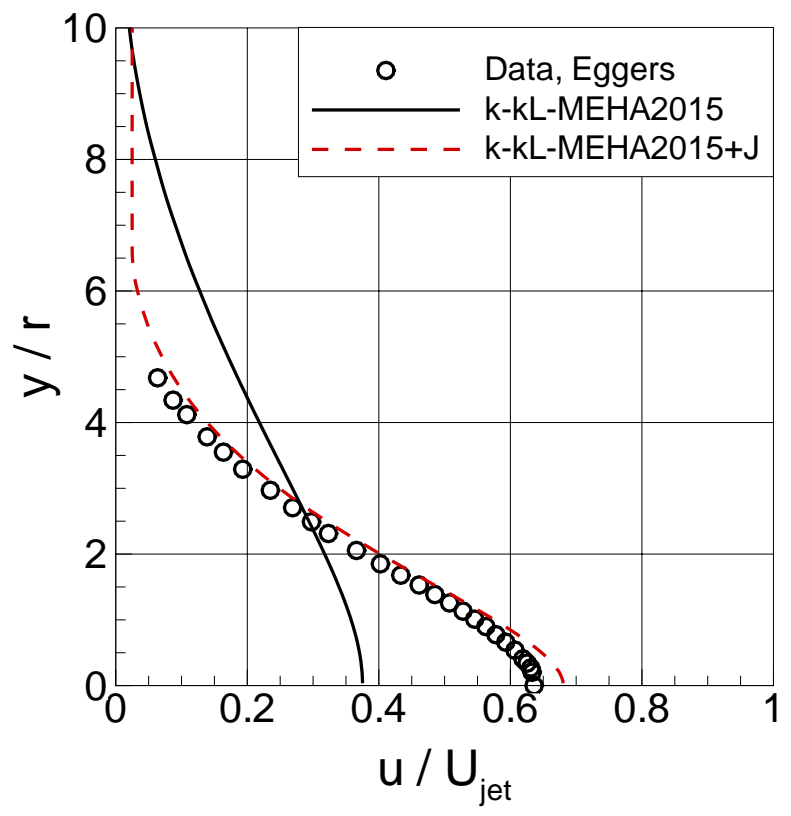

(b) $\mathrm{x} / \mathrm{r}=45.94$.

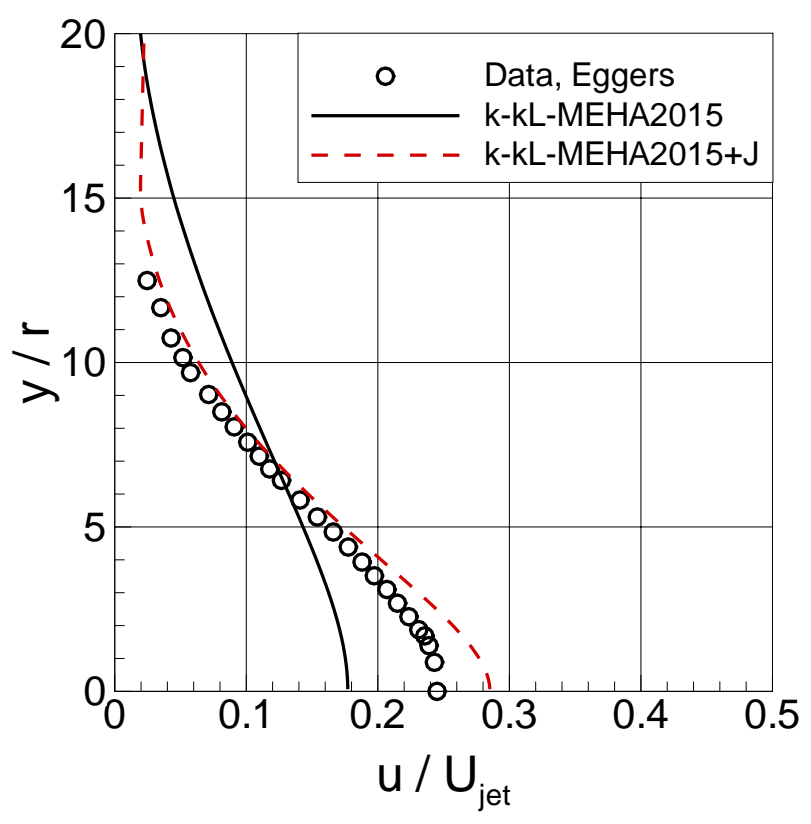

(d) $\mathrm{x} / \mathrm{r}=98.89$.

Figure 23. Effect of jet correction on velocity profiles, Mach 2. jet. symbols, DataEggers [28]; lines, FUN3D. 


\section{Summary}

With the exception of Reynolds stress, the turbulent kinetic energy is exclusively used as one of the transport equations in multi-equation turbulence models. The foundation of this equation is well established and accepted. The scale-determining equation, though, is considered the weakest link, even when full Reynolds stress and hybrid RANS/LES formulations are considered. The first objective of this report is to validate and verify the implementation of the newly developed turbulence model k-kL-MEAH2015 in both CFL3D and Fun3D CFD codes. Rotta shows that a reliable scale-determining equation can be formed in a transport equation for the turbulent length scale, L. Rotta's equation is well suited for a term-by-term modeling and shows some interesting features compared to other approaches. The most important difference is that the formulation leads to a natural inclusion of higher order velocity derivatives into the source terms of the scale equation. Five steady-state test cases were computed and presented, including an attached flow flat plate, 2D bump, separated flow, shear flow, and jet flow cases.

The flat plate and 2D bump are verification cases that use 5 grid levels in a convergence study. All the verification cases show grid convergence and independent solutions. The implementation of k-kL-MEAH2015 in both CFL3D and Fun3D is verified from these results. The flat plate case is also used as a validation case and compared with theoretical data. The results from these cases are compared with theory and experimental data, as well as with results using the SST turbulence model. They demonstrate that the k-kLMEAH2015 model has the ability to produce results similar or better than SST results. The size of the separation bubble (separation and re-attachment locations) is better predicted by k-kL-MEAH2015 model for the separated axisymmetric transonic bump case.

Additionally, the k-kL-MEAH2015 model with jet correction gives better agreement with experimental data than the basic k-kL-MEAH2015 and SST models for the subsonic, near-sonic and supersonic jet cases.

\section{References}

1. Launder, B. E. and Spalding, D. B.: Lectures in mathematical models of turbulence, Academic Press, London, 1972.

2. Rotta, J.: "Statistische Theorie nichthomogener Turbulenz," Zeitschrift für Physik, Vol. 129, No. 6, 1951, pp. 547-572.

3. Menter, F. R.; Egorov, Y. and Rusch, D.: "Steady and Unsteady Flow Modeling Using the k- $\sqrt{\mathrm{k} L}$ model," Turbulence, Heat and Mass Transfer, 5th International symposium, Proceedings, eds. K. Hanjalic̀, Y. Nagano and S. Jakirlic, Dubrovnik, Croatia, 2006, pp. 403-406.

4. Menter, F. and Egorov, Y.: "The Scale-Adaptive Simulation Method for Unsteady Turbulent Flow Predictions. Part 1: Theory and Model Description," Flow, Turbulence and Combustion, Vol. 85, No. 1, 2010, pp. 113-138.

5. Egorov, Y.; Menter, F.; Lechner, R. and Cokljat, D.: "The Scale-Adaptive Simulation Method for Unsteady Turbulent Flow Predictions. Part 2: Application to Complex Flows," Flow, Turbulence and Combustion, Vol. 85, No. 1, 2010, pp. 139-165.

6. Menter, F. R.: "Improved Two-Equation k- $\omega$ Turbulence Models for Aerodynamic Flows," NASA TM-103975, Oct. 1992. 
7. Abdol-Hamid, K. S.: "Assessments of k-kl Turbulence Model Based on Menter's Modification to Rotta's Two-Equation Model," International Journal of Aerospace Engineering, Vol. 2015, 2015, pp. 1-18.

8. Abdol-Hamid, K. S.; Pao, S. P.; Hunter, C.; Deere, K.; Massey, S. and Elmiligui, A.: "PAB3D: It's History in the Use of Turbulence Models in the Simulation of Jet and Nozzle Flows," AIAA Paper 2006-0489, Jan. 2006.

9. http://turbmodels.larc.nasa.gov, accessed: 2015-09-01.

10. Rumsey, C.; Smith, B. and Huang, G.: "Description of a Website Resource for Turbulence Model Verification and Validation," AIAA Paper 2010-4742, June 2010.

11. Krist, S. L.; Biedron, R. T. and Rumsey, C. L.: "CFL3D User's Manual (Version 5.0)," NASA TM-1998-208444, June 1998.

12. Roe, P. L.: "Approximate Riemann Solvers, Parameter Vectors, and Difference Schemes," J. Comp. Phys., Vol. 43, 1981, pp. 357-372.

13. Batten, P.; Clarke, N.; Lambert, C. and Causon, D.: "On the Choice of Wavespeeds for the HLLC Riemann Solver," SIAM J. Sci. Comput., Vol. 18, 1997, pp. 1553-1570.

14. Sun, M. and Takayama, K.: "Artificially Upwind Flux Vector Splitting Scheme for the Euler Equations," J. Comp. Phys., Vol. 189, 2003, pp. 305-329.

15. Edwards, J.: "A Low-Diffusion Flux-Splitting Scheme for Navier Stokes Calculations," AIAA Paper 1996-1704, May 1996.

16. van Leer, B.: "Towards the Ultimate Conservative Difference Schemes V. A second order sequel to Godunov's Method," J. Comp. Phys., Vol. 32, 1979, pp. 101-136.

17. Roe, P. L.: "Characteristic-Based Schemes for the Euler Equations," Annual Review of Fluid Mechanics, Vol. 18, 1986, pp. 337-365.

18. Barth, T. and Jespersen, D.: "The Design and Application of Upwind Schemes on Unstructured Meshes," AIAA Paper 1989-0366, Jan. 1989.

19. Venkatakrishnan, V.: "Convergence to Steady State Solutions of the Euler Equations on Unstructured Grids with Limiters," J. Comp. Phys., Vol. 118, 1995, pp. 120-130.

20. Anderson, W. and Bonhaus, D.: "An Implicit Upwind Algorithm for Computing Turbulent Flows on Unstructured Grids," Computers and Fluids, Vol. 23, No. 1, 1994, pp. $1-22$.

21. Anderson, W.; Rausch, R. and Bonhaus, D. L.: "Implicit/Multigrid Algorithms for Incompressible Turbulent Flows on Unstructured Grids," J. Comp. Phys, Vol. 128, 1996, pp. 391-408.

22. Schoenherr, K. E.: Resistance of Flat Surfaces Moving Through a Fluid, Ph.D. thesis, Johns Hopkins University, 1932.

23. Coles, D.: "The law of the wake in the turbulent boundary layer," J. Fluid Mech., Vol. 1, 1956, pp. 191-226.

24. Bradbury, L. J. S. and Riley, J.: "The spread of a turbulent plane jet issuing into a parallel moving airstream," J. Fluid Mech., Vol. 27, 1967, pp. 381-394. 
25. Bachalo, W. D. and Johnson, D. A.: "Transonic, turbulent boundary-layer separation generated on an axisymmetric flow model," AIAA Journal, Vol. 24, No. 3, 1986, pp. 437-443.

26. Bridges, J. and Brown, C.: "Parametic Testing of Chevrons on Single Flow Hot Jets," AIAA Paper 2004-2824, 2004.

27. Seiner, J. M.; Ponton, M. K.; Jansen, B. J. and Lagen, N. T.: "The Effects of Temperature on Supersonic Jet Noise Emission," DGLR / AIAA Aeroacoustics Conference, 14th, Proceedings, Vol. 1, (A93-19126 05-71), Aachen, GERMANY, May 1992, pp. 295-307.

28. Eggers, J.: "Velocity Profiles and Eddy Viscosity Distributions Downstream of a Mach 2.22 Nozzle Exhausting to Quiescent Air," NASA TN D-3601, September 1966.

29. http://www.grc.nasa.gov/WWW/wind/valid/seiner/Seiner.html, accessed: 201509-10.

30. http://www.grc.nasa.gov/WWW/wind/valid/axinoz/axinoz.html, accessed: 201509-10. 


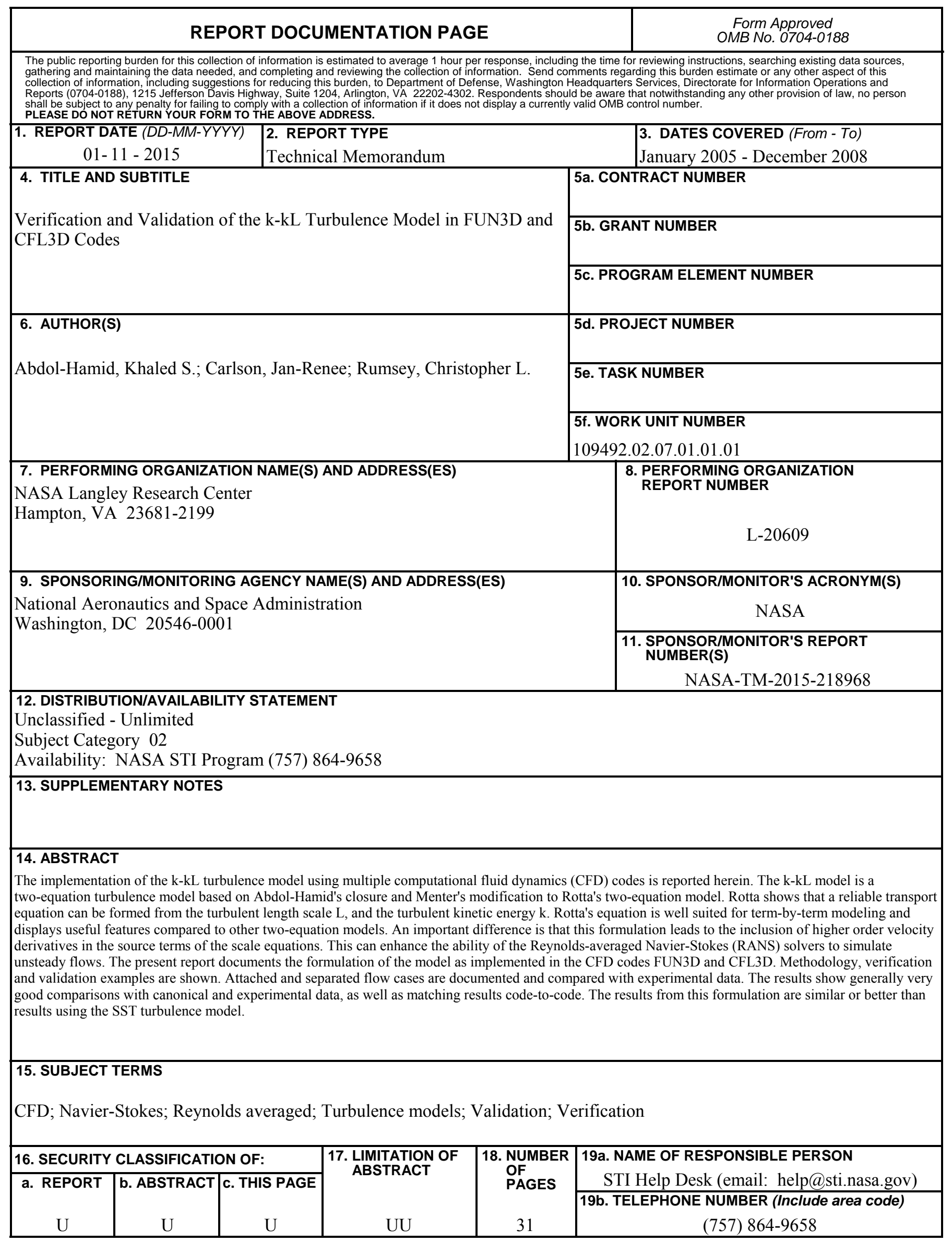

